UNIVERSIDADE ESTADUAL PAULISTA -UNESP

FACULDADE DE MEDICINA DE BOTUCATU

PROGRAMA DE PÓS GRADUAÇÃO FISIOPATOLOGIA EM CLÍNICA MÉDICA

Chiara de Campos Legnaro

Padrão de metilação dos genes CDH1, BRCA1, hMLH1 e polimorfismos das enzimas TS e MTHFR do ciclo do folato em tecido tumoral mamário 
Chiara de Campos Legnaro

Padrão de metilação dos genes CDH1, BRCA1, hMLH1 e polimorfismos das enzimas TS e MTHFR do ciclo do folato em tecido tumoral mamário

Dissertação apresentada ao
Programa de Pós Graduação
Fisiopatologia em Clínica
Médica da Faculdade de
Medicina de Botucatu-Unesp,
para obtenção do título de
Mestre em Ciências da
Saúde.

Orientadora: Dra. Maria Inês de Moura Campos Pardini 


\section{DEDICATÓRIA}

Este trabalho e tudo mais em nossas vidas

seriam impossível sem vocês. Minha eterna gratidão e admiração por tudo que fizeram por mim e meus irmãos.

Dedico esse trabalho aos meus pais. 


\section{AGRADECIMENTOS}

- A Deus, pelo dom da vida, pela luz que me guia e me protege.

- A Nossa Senhora e meu Anjo da Guarda, pela intercessão e proteção.

- Aos meus pais, pelo apoio incondicional, pelos ensinamentos e exemplos dados durante toda minha vida que hoje me fazem o que sou.

- A toda minha família, principalmente aos meus irmãos, Inah e Hugo, pelo apoio e compreensão.

- A minha sobrinha Cecília que mesmo sem saber, com seu olhar doce e sorriso meigo, muitas vezes, foi minha maior fonte de ânimo.

- A Dra. Maria Inês Pardini por ter me recebido no laboratório e me dado a oportunidade de iniciar a pós graduação.

- Ao programa de Pós Graduação Fisiopatologia em Clínica Médica da Faculdade de Medicina de Botucatu- Unesp.

- Aos docentes do Programa de Pós Graduação pelos ensinamentos

- A Dra. Silvia e todos os integrantes do seu grupo de pesquisa da Faculdade Federal do Ceará.

- Ao professor Dr. Carlão pela análise estatística.

- A Dra. Claúdia (IB) e a as integrantes do seu grupo de pesquisa, pelas "figurinhas trocadas", apoio e recepção.

- A Dra. Adriana, pela ajuda com o protocolo de tratamento com bissulfito de sódio.

- Ao Hemocentro, representado pelo Dr. José Mauro Zanini, por toda a infra estrutura cedida para realização deste trabalho.

- A Cléo e a Janisse, por tantos favores prestados.

- Aos funcionários da secretaria de pós graduação, que são exemplo de bom atendimento, educação, paciência e eficiência. 
- Aos funcionários da biblioteca.

- A Jaque pela arte da capa.

- Aos amigos inesquecíveis de laboratório: Jú, Camilinha, Kamila, Marcinha, Denise, Má, Patrícia e Juliano, pelo incentivo, pelo aprendizado que tantas vezes construímos juntos e principalmente pela amizade sincera, festas, churrascos, muitas risadas e outras coisas mais...

- A Bete, pela amizade e paciência, por ser a "mãezona" de todos que passam pelo laboratório.

- As meninas e o Maércio do "laboratório da rotina" pela companhia.

- A todos que não estiveram comigo no laboratório, mas que de uma maneira ou de outra, me ajudaram e torceram por mim.

- A Bacuri, mas que amiga de república uma irmã que conheci em Botucatu.

- Aos integrantes das repúblicas "Velhas Virgens", "Asilo da Tenente" e "Pé de Frango", pela amizade, companheirismo, festas e muito mais...

- Aos amigos de Iacanga e Botucatu que compreenderam tantas ausências.

- Aos amigos, professores e funcionários da FATEC, que me ajudam tanto, me fazem rir e relaxar todas as noites. 


\section{EPÍGRAFE}

Não vemos as coisas como

elas são: vemos as coisas como somos.

Anais Nin 


\section{PREFÁCIO}

Iniciei minhas atividades no Laboratório de Biologia Molecular do Hemocentro da Faculdade de Medicina de Botucatu- Unesp em 2005 como estagiária em um grupo de pesquisa dedicado ao estudo do câncer gástrico. Neste mesmo ano, tive a oportunidade de participar como bolsista técnica, do final da "tarefa HIV" e da "tarefa HCV" do projeto VGDN (Viral Genetic Diversity Network).

Em 2006/2007 cursei o Programa de Aprimoramento Profisional: "Inovação Tecnológica em Pesquisa e Diagnóstico Laboratorial". Neste curso, além de colaborar com as atividades do VGDN, tive como objetivo a padronização da reação de sequenciamento do DNA de 6 regiões do Complexo Principal de Histocompatibilidade (MHC) de pacientes HIV positivos.

Ao final de 2007 realizei o exame de seleção para o Programa de Pós Graduação Fisiopatologia em Clínica Médica com uma proposta de projeto a ser desenvolvido em parceria entre o Hemocentro de Botucatu - Unesp e o Laboratório de Genética Molecular da Universidade Federal do Ceará, local articulador da coleta das 54 amostras de tecido tumoral mamário utilizadas neste trabalho e responsável pela detecção dos polimorfismos.

O objetivo do trabalho foi determinar a associação do padrão de metilação dos genes CDH1, BRCA1 e hMLH1 com a frequência dos polimorfismos C677T e A1298C do gene da metilenotetrahidrofolato redutase (MTHFR) e $2 R / 3 R$ da timidilato sintase (TS), buscando sugerir marcadores de vias tumorigênicas do epitélio mamário baseados na alteração do padrão de metilação dos genes supressores tumorais que pudessem ser decorrente dos polimorfismos das enzimas do ciclo do folato. 
O trabalho foi redigido constando de uma introdução geral, para contextualização do Projeto, e um artigo científico que deverá ser publicado, após as correções, em revista sugerida pela Banca Examinadora. 


\section{RESUMO}

O câncer de mama é o tipo de câncer mais comum entre as mulheres, correspondendo a $22 \%$ de todos os casos. Foram estimados mais de 1.050.000 casos novos de câncer de mama em todo o mundo no ano 2000. Mecanismos epigenéticos como a ativação e desativação de genes por meio da hipometilação e hipermetilação, respectivamente, da região promotora dos genes estão associados ao surgimento de diversos tipos de cânceres. Embora os fatores que resultam na metilação aberrante ainda não sejam bem conhecidos, a deficiência de folato têm sido associada a esse mecanismo no desenvolvimento de cânceres como de colo uterino, pulmão, mama, cólon e cérebro. Neste trabalho, foi avaliado se os polimorfismos em genes de enzimas chaves no metabolismo do folato como a timidilato sintase (TS) e metilenotetrahidrofolato redutase (MTHFR) influenciam o padrão de metilação da região promotora dos genes $C D H 1$, BRCA1 e hMLH1 em amostras de câncer de mama. A metilação foi avaliada através da MS-PCR e os polimorfismos por PCR e PCR-RFLP. Não houve diferença estatisticamente significante $(p<0.05$, teste exato de Fisher) do padrão de metilação dos genes quando comparado com estádio, grau histológico, idade e freqüência dos polimorfismos. Os polimorfismos 5'UTR TS, C677T e A1298C MTHFR não influenciam no padrão de metilação da região promotora dos genes CDH1, BRCA1 e hMLH1 em amostras de câncer de mama.

Palavras chave: câncer de mama; metilação; polimorfismo MTHFR / TS; genes supressores. 


\begin{abstract}
The breast cancer is the most frequent cancer in women equivalent to $22 \%$ of all cases. It were estimated more than 1.050 .000 new cases of breast cancer in all the world in the year 2000. Epigenetic mechanisms like ativation and desativation of genes by hypomethylation and hipermethylation, respectivelly, of genes promoter regions are associated to the appearance of several types of cancer. Although the factors that result in aberrant methylation are not well known, the lack of folate has been associated to this mechanism in the development of cancers like cervical uterine, lungs, breast, colon and brain. In this research it was evaluated if the polymorphisms in genes of folate metabolism enzymes like the thymidilate syntase (TS) and methylenetetrahydrofolate reductase (MTHFR) influence the methylation pattern of the promoter of genes $C D H 1$, $B R C A 1$ and $\mathrm{hMLH} 1$ in samples the tissue of breast cancer. The methylation was evaluated through the MS-PCR and the polymorphisms through PCR and PCR-RFLP. We observed no statistically significant associations $(p<0.05$, exact test of Fisher) of the patterns of methylation of genes when compared to stage, histologic grade, age and frequency of polymorphisms. The polymorphisms 5'UTR TS, C677T AND A1298C $M T H F R$ did not influence in the pattern of methylation of the promoter region of genes $C D H 1, B R C A 1$ e $h M L H 1$ in samples the tissue of breast cancer.
\end{abstract}

Keywords: breast cancer; methylation; polimorphisms MTHFR/TS; suppressor genes. 


\section{LISTA DE FIGURAS}

Figura 1. Incidência, por 100.000 habitantes, do câncer de mama feminino (Adaptado de Parkin, 2004.)

Figura 2. Grupamentos para classificação TNM. $T=$ tamanho do tumor; $N=$ linfonodos regionais; $M=$ metástase a distância (Adaptado INCA, 2004).

Figura 3. Esquema de ilhas CpGs não metiladas (a) e metiladas (b) (Adaptado Jacinto \& Esteller, 2007.).

Figura 4. Representação do metabolismo do ácido fólico (Adaptado Suzuki et al., 2008.) 


\section{SUMÁRIO}

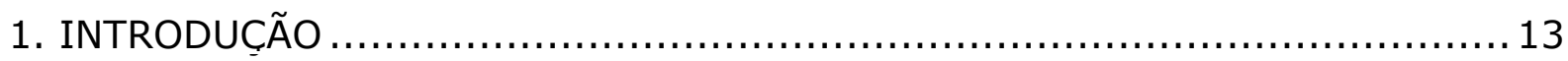

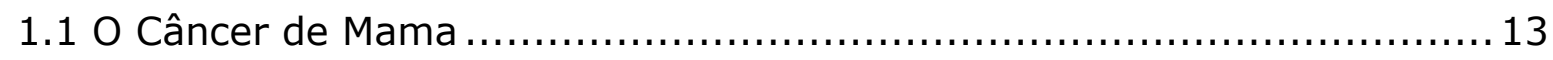

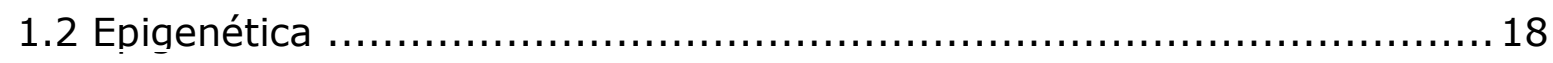

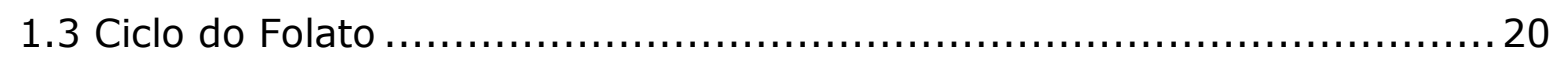

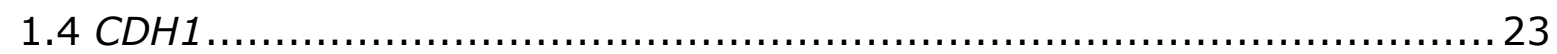

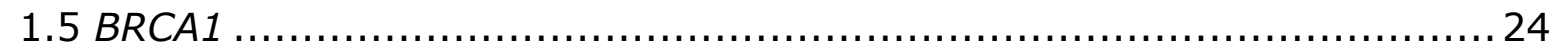

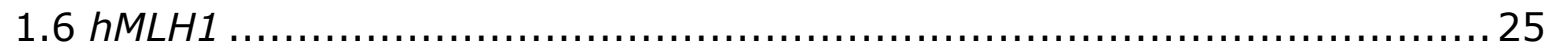

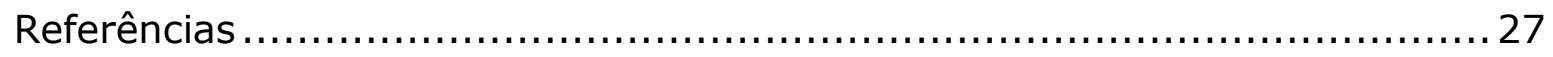

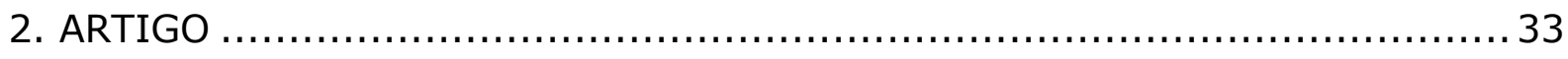

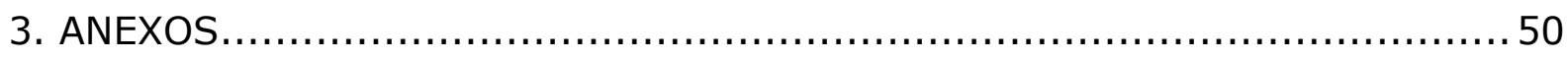




\section{INTRODUÇÃO}

\subsection{O Câncer de Mama}

O câncer de mama ( $\mathrm{CM}$ ) é o tipo de câncer mais comum entre as mulheres, correspondendo a $22 \%$ de todos os casos de câncer. Foram estimados mais de 1.050 .000 casos novos de CM em todo o mundo no ano 2000, sendo a maioria em países industrializados, e menos comum em países em desenvolvimento, embora, essa incidência venha aumentando. Altas taxas de incidência (Figura 1) têm sido observadas nos Estados Unidos, Europa, Austrália, Nova Zelândia, Uruguai e Argentina, ao contrário da África e Ásia (Parkin, 2004).

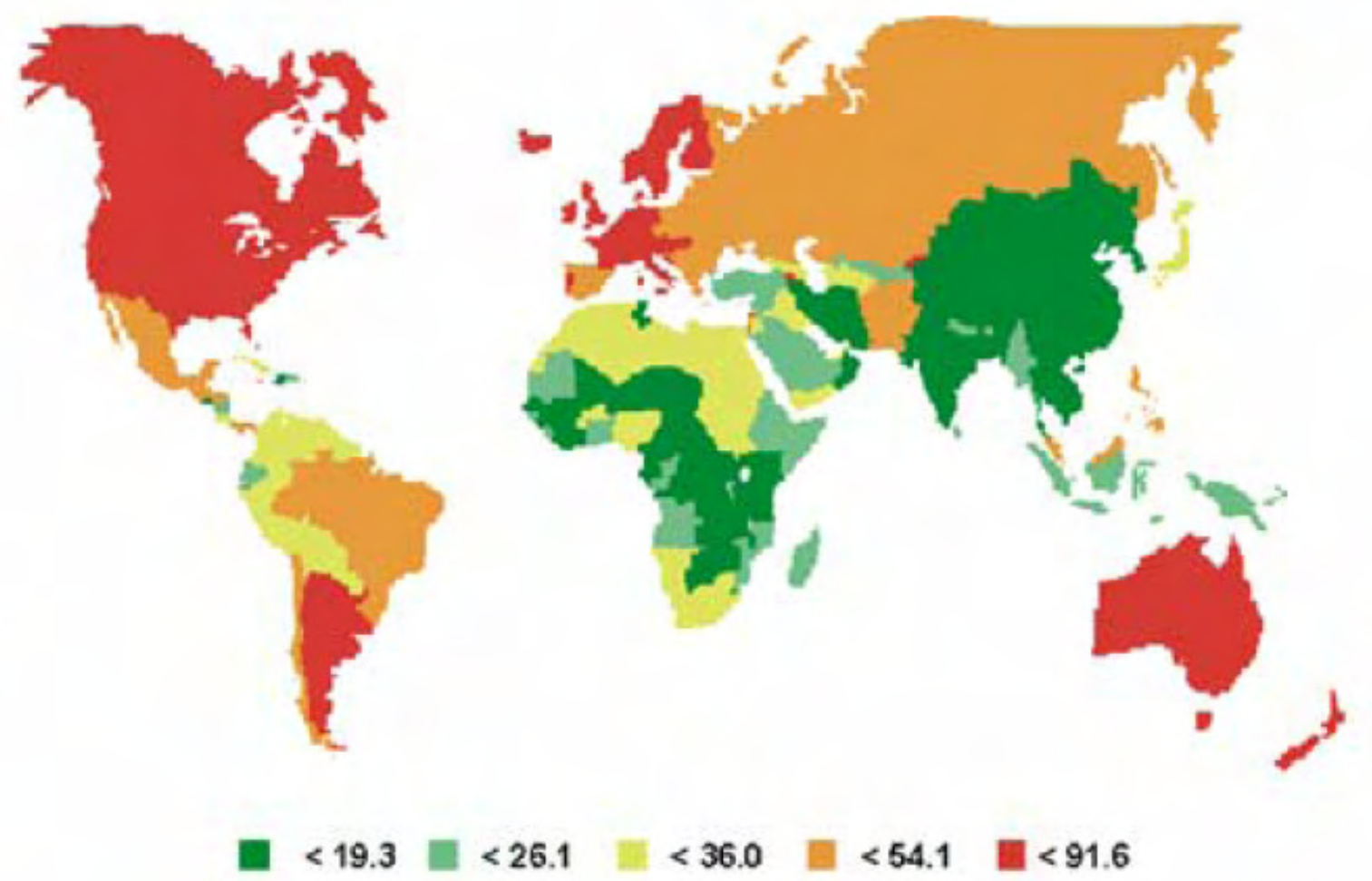

Figura 1. Incidência, por 100.000 habitantes, do câncer de mama feminino (Adaptado de Parkin, 2004). 
Estimativas do Instituto Nacional do Câncer (INCA) para o ano de 2010 apontam que ocorrerão 489.270 casos novos de câncer no Brasil, sendo esperados 236.240 casos novos para o sexo masculino e 253.030 para sexo feminino. Estima-se que o câncer de pele do tipo não melanoma (114 mil casos novos) será o mais incidente na população brasileira, seguido pelos tumores de próstata (52 mil), mama feminina (49 mil), cólon e reto $(28 \mathrm{mil})$, pulmão $(28 \mathrm{mil})$, estômago $(21 \mathrm{mil})$ e colo do útero (18 mil). Entre as mulheres, sem considerar os tumores de pele não melanoma, o tipo mais incidente é o CM com uma estimativa de 49.240 casos novos e um risco estimado de 49 casos a cada 100 mil mulheres. Embora o prognóstico dessa malignidade seja relativamente bom se diagnosticada nos estádios iniciais, no Brasil, as taxas de mortalidade por CM continuam elevadas, tornando-se a primeira causa de morte por câncer entre as mulheres (INCA, 2009).

A carcinogênese é um processo de múltiplos eventos caracterizado por alterações que influenciam as principais vias de sinalização envolvidas no desenvolvimento e crescimento celular (Rakha et al., 2006), criando um desequilíbrio funcional na maquinaria molecular da célula e, conseqüentemente, de suas proteínas, dando condições para que a célula escape do controle normal de crescimento. Essas alterações são eventos iniciais na carcinogênese e podem ser detectadas antes do início dos sintomas e alterações morfológicas. Dentre as principais alterações moleculares, envolvidas na carcinogênese, estão a instabilidade de microsatélete (MSI), polimorfismos de nucleotídeo único (SNPs) e a metilação aberrante do DNA, sendo, esta última, considerada como um promissor biomarcador em genes associados à doenças (Srinivas et al., 2001; Honório, 2003).

A determinação de biomarcadores de tumorigênese é útil na deteç̧ão precoce do câncer, no auxílio da previsão de risco do desenvolvimento tumoral e metástase, estratificação dos pacientes para o tratamento, além de ajudar na vigilância da recorrência da doença (Bast 
et al., 2005). Alguns biomarcadores como acometimento de linfonodos axilares, tamanho do tumor, o tipo e grau histológico, idade da paciente, invasão linfovascular e aumento da proliferação celular, são comumente usados como fatores prognósticos, porém, após a cirurgia, enquanto que os marcadores moleculares podem ser utilizados antes mesmo da instalação da doença (Cianfrocca \& Goldstein, 2004). Atualmente apenas três marcadores moleculares são usados na rotina clínica para o $\mathrm{CM}$, sendo eles o receptor de estrógeno (ESR), receptor de progesterona (PGR) e o receptor de fator de crescimento epidermal (HER-2), tornando-se necessário a validação de novos marcadores moleculares (Murphy et al., 2005).

Os principais fatores de risco para o desenvolvimento do CM são:

- Idade: antes dos vinte e cinco anos a incidência do CM é baixa (menos de dez casos por 100.000 mulheres), porém, esse risco aumenta rapidamente com o avanço da idade, chegando a ser cerca de cem vezes maior por volta dos quarenta e cinco anos.

- Localização geográfica: a incidência e mortalidade do CM variam entre as diferentes populações, sendo mais elevadas em países desenvolvidos e mais baixas nos países em desenvolvimento e no Japão.

- Fatores reprodutivos: mulheres com menarca precoce, antes dos doze anos, e menopausa tardia, depois dos cinquenta e cinco anos, têm um risco mais elevado para o desenvolvimento do CM. Estima-se que para cada ano em que a menarca se retarda o risco diminua cerca de $5 \%$ e, no caso da menopausa, aumenta cerca de $3 \%$ provavelmente pela exposição prolongada do epitélio mamário à hormônios. Neste contexto, os hormônios utilizados em reposição hormonal e o uso de contraceptivos orais também têm sido ligados a um aumento do risco para o CM.

A nuliparidade e idade tardia da primeira gravidez também podem aumentar esse risco. Mulheres que têm o primeiro filho depois dos 
trinta anos têm duas vezes mais chances para desenvolver CM se comparadas com mulheres que deram à luz um filho antes dos vinte anos. Ainda não se sabe se esse efeito protetor atua naquelas em que a gravidez é interrompida. Embora ainda não comprovado, a amamentação prolongada parece ter um efeito protetor, principalmente em mulheres jovens.

- História familiar: estudos mostram que mulheres com parentes de primeiro grau afetados com CM têm um risco relativo de desenvolver o tumor aumentado em duas vezes. Isso pode ser atribuído ao compartilhamento do ambiente físico, estilo de vida e carga genética, principalmente de mutações nos genes BRCA1 e BRCA2 presente em cerca de $10 \%$ dos casos de CM nos países desenvolvidos.

- Doenças benignas da mama: pacientes que apresentam doenças benignas da mama como hiperplasia epitelial atípica, por exemplo, têm o risco aumentado em quatro a cinco vezes para desenvolver CM (McPherson et al., 2000; Key et al., 2001; Dumitrescu \& Cotarla, 2005).

Apesar de existirem vários tipos e subtipos histológicos do carcinoma mamário, tornando-o uma doença complexa e clinicamente heterogênea, $95 \%$ dos casos são ductais ou lobulares e podem se apresentar nas formas in situ ou invasiva. A maioria (75 - 80\%) dos carcinomas mamários são ductais, sendo os carcinomas ductais invasivos (CDI) caracterizados pela formação de túbulos ou ductos que se infiltram no parênquima mamário. Os CDI são avaliados por três características histológicas, o grau de atipia nuclear, o nível de atividade mitótica e a extensão da formação dos ductos, as quais são atribuídos valores numéricos que formam o score Bloom-Richardson, que resulta na classificação do grau histológico do câncer em bem diferenciado (grau I), moderadamente diferenciado (grau II) e pouco diferenciado (grau III). Essa classificação histológica tem grande importância prognóstica, pois, estudos demonstram correlação direta com freqüência de metástase em 
linfonodos, freqüência de recorrência da doença e morte causada por carcinoma invasivo (Yoder et al., 2007).

Para estadiamento TNM utiliza-se os critérios da União Internacional Contra o Câncer (UICC) TNM: classification of malignant tumours, 6th ed. (INCA, 2004). Para esta classificação são usados os seguintes parâmetros: $\mathrm{T}=$ tamanho do tumor; $\mathrm{N}=$ acometimento de linfonodos regionais; $M=$ metástase a distância. $O$ quadro a seguir mostra um esquema do estadiamento por grupamentos.

\begin{tabular}{|c|c|c|c|}
\hline \multicolumn{4}{|c|}{ Grupamento por Estádios } \\
\hline Estádio 0 & Tis & NO & M0 \\
\hline Estádio I & $\mathrm{T} 1$ & NO & M0 \\
\hline \multirow{3}{*}{ Estádio IIA } & T0 & N1 & MO \\
\hline & $\mathrm{T} 1$ & N1 & M0 \\
\hline & T2 & NO & M0 \\
\hline \multirow{2}{*}{ Estádio IIB } & T2 & N1 & M0 \\
\hline & T3 & NO & MO \\
\hline \multirow{4}{*}{ Estádio IIIA } & TO & N2 & MO \\
\hline & $\mathrm{T} 1$ & N2 & MO \\
\hline & T2 & N2 & M0 \\
\hline & T3 & $\mathrm{N} 1, \mathrm{~N} 2$ & M0 \\
\hline Estádio IIIB & T4 & $\mathrm{N} 0, \mathrm{~N} 1, \mathrm{~N} 2$ & M0 \\
\hline Estádio IIIC & Qualquer T & N3 & M0 \\
\hline Estádio IV & Qualquer T & Qualquer N & M1 \\
\hline
\end{tabular}

Figura 2. Grupamentos para classificação TNM. T= tamanho do tumor; $\mathrm{N}=$ linfonodos regionais; $\mathrm{M}=$ metástase a distância (Adaptado INCA, 2004). 


\subsection{Epigenética}

Mecanismos epigenéticos são aqueles que levam a alteração na expressão de genes durante o desenvolvimento e proliferação celular, porém, sem nenhuma mudança na seqüência dos nucleotídeos. Estudos têm mostrado que a epigenética tem papel importante na biologia do câncer e, por serem reversíveis, tornaram-se importante alvo terapêutico. A metilação do DNA é um dos eventos epigenéticos mais comum no genoma de mamíferos (Singal \& Ginder, 1999).

A metilação do DNA é uma modificação química, resultando na adição de um grupo metil $(\mathrm{CH} 3)$ no carbono $5^{\prime}$ da citosina que está próxima a uma guanina, também chamada de dinucleotídeo CpG (Ramsahoye et al., 2000). A maioria dos dinucleotídeos CpGs está desigualmente distribuída pelo genoma e se apresenta em trechos curtos, de 500-2000 pb, denominados ilhas CpGs (Lair \& Jaenisch, 1996). Essas ilhas estão localizadas na região promotora e são encontradas em, pelo menos, metade de todos os genes humanos (Baylin, 2005).

Quando a expressão do gene é controlada pela metilação do DNA (Figura 2), ele pode ser categorizado de duas formas: hipometilado ou hipermetilado. O DNA hipometilado é associado com superexpressão de proto-oncogenes, aumento de recombinação e mutação e perda do imprinting nos cânceres (Esteller \& Herman, 2002). Quando as ilhas CpGs estão hipermetiladas, a atividade das proteínas reguladoras que promovem a transcrição é restrita devido ao alto empacotamento dos nucleossomos, resultando na inativação de genes (Esteller et al., 2001 ; Baylin, 2005). Ambos os tipos de metilação ocorrem simultaneamente em vários cânceres esporádicos afetando a função de genes supressores tumorais e proto-oncogenes (Balch et al., 2005). 
Um potencial marcador câncer-específico, que tem atraído a atenção dos pesquisadores é a hipermetilação aberrante do DNA, comumente vista em células cancerígenas e freqüentemente coincidindo com silenciamento gênico (Jones \& Baylin, 2002; Patel et al., 2003). A metilação aberrante do DNA pode conferir à célula vantagem seletiva de crescimento. Nos diversos tipos de cânceres, são observadas metilações aberrantes em regiões específicas de genes que, em tecidos normais, são protegidas (Costello et al., 2000).

a)

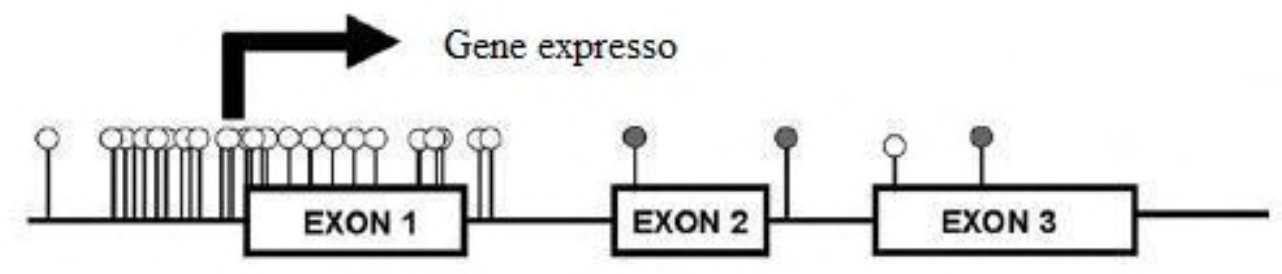

b)

)

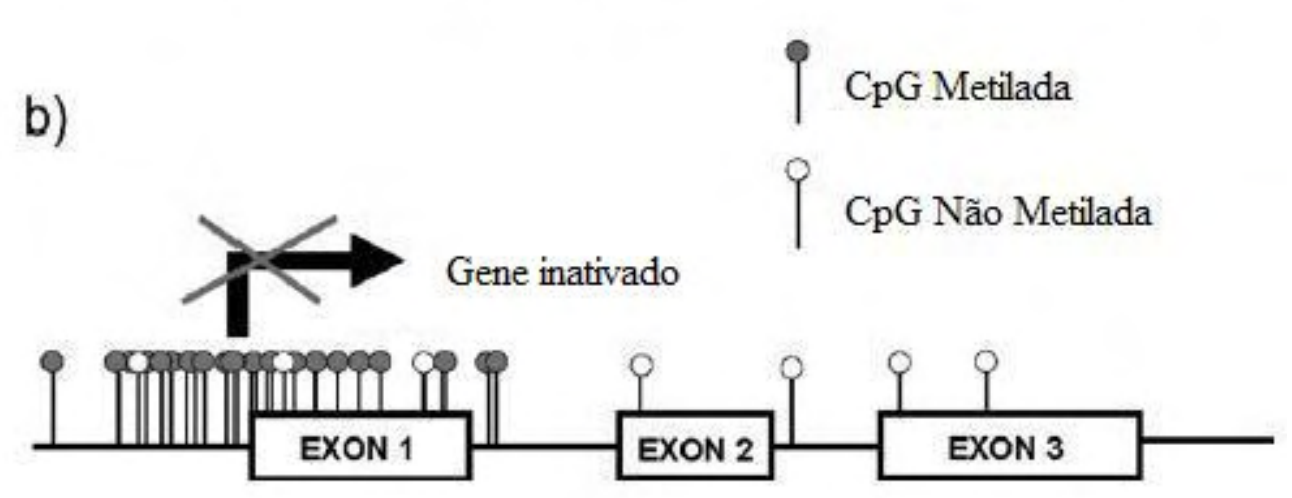

Figura 3. Esquema de ilhas CpGs não metiladas (a) e metiladas (b) (Adaptado Jacinto \& Esteller, 2007).

O DNA é metilado pelas enzimas da família das DNA metiltransferases (DNMTs) que são responsáveis pela trasnferência do grupo metil através da S-adenosilmetionina (SAM) (Gopisetty et al., 2006).

A DNMT1 mantém estáveis padrões de metilação estabelecidos, copiando, durante a replicação celular, a metilação da fita mãe para fita 
filha (Agoston et al., 2005). A DNMT2, é uma pequena proteína de 391 aminoácidos, conhecida por ter fraca atividade DNA metiltransferase (Chen \& Li, 2006). A DNMT3a e DNMT3b, fazem a metilação de novo de DNA não metilado. Elas iniciam a metilação normal durante o desenvolvimento embrionário. A DNMT3L não tem ligação com a SAM, porém, é essencial para o processo de metilação, pois, aumenta a ligação da DNMT3a com a SAM (Jaenisch, 1997).

Embora a atividade das DNMTs esteja envolvida na baixa expressão de genes supressores de tumor e na estimulação de protooncogenes ( Robertson et al., 2000), muitos achados indicam que esse fator isolado não seja fundamental para a promoção da carcinogênese (Eads et al., 1999).

\subsection{Ciclo do Folato}

O ácido fólico, uma das vitaminas $B$, atua como cofator de várias reações bioquímicas mediante sua capacidade de doar e receber unidades de carbono. Os mamíferos são incapazes de sintetizar ácido fólico de novo devendo obtê-lo na dieta. A deficiência de folato foi relatada como a deficiência de vitamina mais comum nos Estados Unidos, afetando $10 \%$ da população adulta em geral, e $60 \%$ dos jovens e idosos de baixo nível sócio econômico (Senti \& Pilch, 1985). Já se sabe que sua deficiência causa anemia grave em humanos, e que na gravidez está relacionada com defeitos do tubo neural no recém nascido (Czeizel, 1993). Carência de folato também é considerada um fator de risco independente para doenças cardíacas, devido a níveis elevados de homocisteína (Boushey et al., 1995).

No entanto, mais recentemente, a deficiência de folato têm sido associada ao desenvolvimento de cânceres como de colo uterino, pulmão, mama, cólon e cérebro. Dois mecanismos têm sido propostos para 
explicar como o folato, e os polimorfismos em suas enzimas chaves do metabolismo, podem influenciar o risco para o câncer. O primeiro é mediante a alteração do padrão de metilação, o segundo, é pela da incorporação errada da uracila na síntese do DNA. Contudo, evidências, em humanos, que suportem esses mecanismos ainda são limitadas (Duthie, 1999).

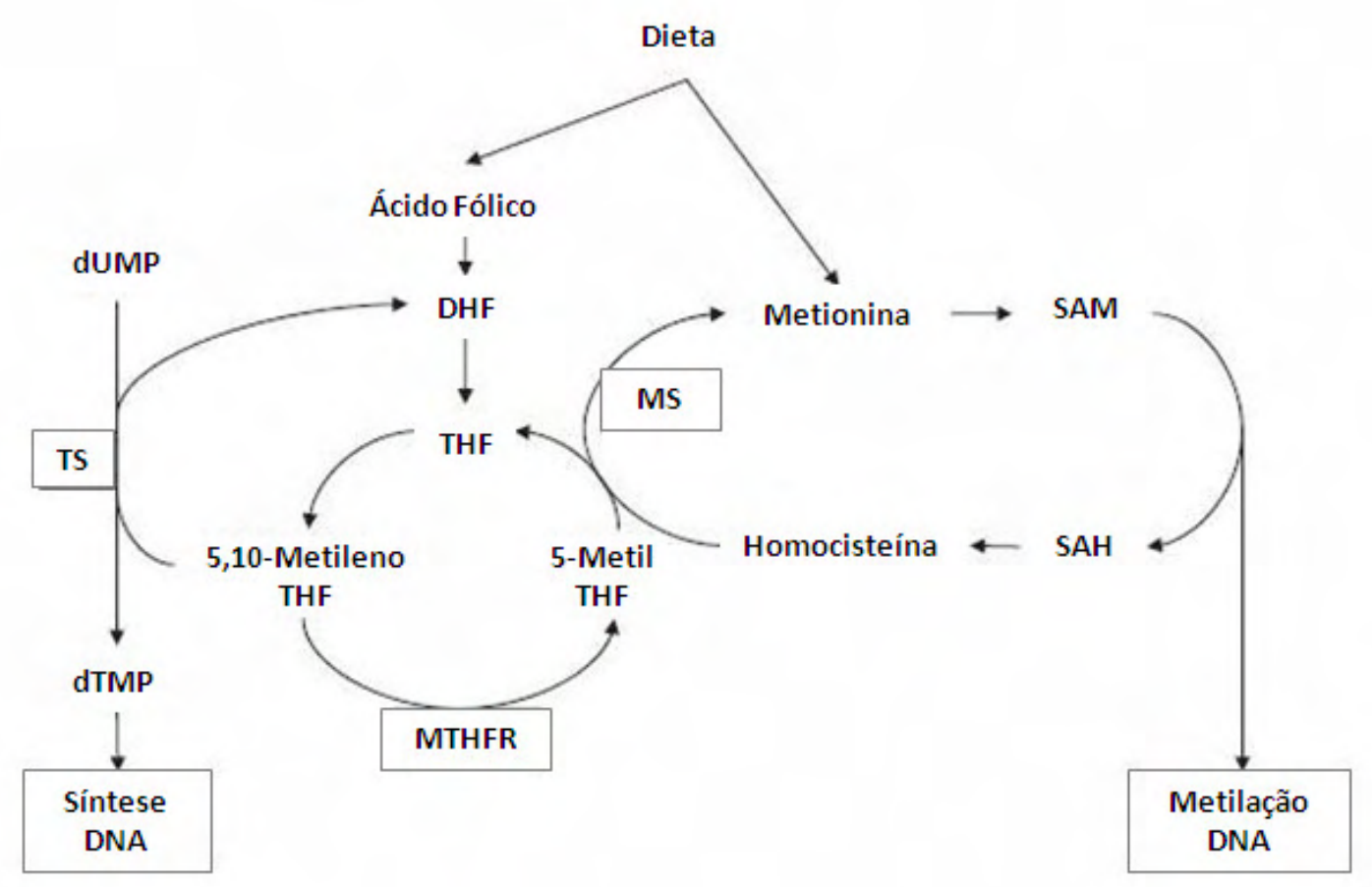

Figura 4. Representação do metabolismo do ácido fólico (Adaptado Suzuki et al., 2008).

Vários estudos têm mostrado a importância da adequada ingestão de folato na prevenção do câncer. Em estudos com roedores, a deficiência de metil na dieta diminuiu a concentração de SAM nos tecidos produzindo um DNA hipometilado no fígado (Pogribny et al., 1995). Em humanos, a deficiência de folato pode levar a hipometilação do DNA, incorporação errada da uracila, danos nos cromossomos, (Jacob et al., 1998) e sendo, consequentemente, implicada no desenvolvimento de 
vários tipos de cânceres epiteliais como útero, pulmão e mama ( Glynn \& Albanês, 1994). Além disso, polimorfismos em genes de enzimas chaves no metabolismo do folato como a timidilato sintase (TS) e metilenotetrahidrofolato redutase (MTHFR) também podem influenciar o risco para desenvolvimento de câncer (Goyette et al., 1994).

A TS é uma enzima que catalisa a conversão da deoxiuridina monofosfato (dUMP) em deoxitimidina monofosfato (dTMP) usando o 5,10-metilenotetrahidrofolato como doador de radical metil. Seu gene está localizado no cromossomo 18p11.32 (Sharp \& Little, 2004). Ela é responsável pelo equilíbrio e oferta de nucleotídeos necessários para a replicação e reparo do DNA, sendo assim, essencial para a proliferação celular e também um importante alvo para as drogas anti câncer (Ulrich et al., 2000).

Foi identificado um polimorfismo na região promotora $5^{\prime}$ UTR do $T S$, imediatamente acima do códon de iniciação ATG, que contém dupla (2R) ou tripla (3R) repetição de uma seqüência de 28 pb e, raramente, alelos com 4, 5 ou 9 repetições. Estudos in vitro e in vivo, mostraram que a expressão da TS é aumentada quando apresenta o alelo 3R (Horie et al., 1995).

A MTHFR é uma importante enzima regulatória do metabolismo do folato. Ela catalisa a conversão do 5,10-metilenotetrahidrofolato em 5metiltetrahidrofolato, principal forma circulante do folato, responsável por doar radical metil para remetilação da homocisteína em metionina. Além disso, ela controla se o folato será usado na síntese ou na metilação do DNA. O gene da MTHFR está localizado no cromossomo 1p36 (Goyette et al., 1994) e o polimorfismo mais comumente encontrado é a troca de uma citosina por uma timina no nucleotídeo 677 (C677T) resultando na troca de uma valina por uma alanina na proteína. Esse polimorfismo está associado a uma maior termolabilidade e uma considerável diminuição da atividade enzimática. Os homozigotos (TT) e os heterozigotos (CT), 
apresentaram, in vitro, apenas 30\% e $60 \%$ da atividade enzimática, respectivamente (Frosst et al., 1995). O polimorfismo A1298C no gene da MTHFR resulta na troca de um ácido glutâmico por uma alanina em sua proteína e também está associado à diminuição da atividade enzimática in vitro (Weisberg et al., 1998).

\section{$1.4 \mathrm{CDH} 1$}

O gene $\mathrm{CDH1}$ está localizado no cromossomo 16q22.1. Seu produto é a E-caderina, uma glicoproteína dependente de cálcio, importante para a adesão celular, desenvolvimento e manutenção do fenótipo epitelial (Overduin et al., 1995). A proteína E-caderina é altamente expressa em epitélio normal e diminuída ou ausente em vários carcinomas humanos como o de cólon, estômago, próstata, fígado, bexiga e mama (Gumbiner, 2000). Alterações na expressão da E-caderina têm sido correlacionadas com fatores patológicos como pior diferenciação tumoral, crescimento infiltrante, metástase e diminuição da sobrevida do paciente (Hirohashi, 1998; Debbies \& Welch, 2001).

Os mecanismos de redução ou perda da expressão da E-caderina em cânceres sólidos ainda não são totalmente compreendidos. Mutações, (Guilford et al., 1998) perda de heterozigose (LOH), (Frixen et al., 1991) rearranjo da cromatina (Hennig et al., 1995) e hipermetilação das ilhas CpG da região promotora ( Graff et al., 1995) são eventos que podem estar envolvidos na inativação do $C D H 1$.

A perda ou a baixa expressão da E-caderina tem sido amplamente documentada no câncer de mama, com a atuação de mecanismos irreversíveis (genéticos) e reversíveis (epigenéticos) (CletonJansen, 2002). No carcinoma ductal de mama a perda da expressão da Ecaderina é heterogênea nos diferentes estádios, sugerindo que o mecanismo de perda da expressão nesses tumores não envolve somente 
alterações genéticas (Mareel et al., 1995). Caldeira et al. (2006), observaram hipermetilação da região promotora do $C D H 1$ em $72 \%$ (52/71) dos carcinomas ductais.

\section{$1.5 B R C A 1$}

Embora a genética da carcinogênese mamária ainda não esteja bem elucidada, já se sabe que o gene BRCA1 está intimamente relacionado com os casos hereditários do câncer de mama e ovário (Miki et al., 1994) e que, nos casos esporádicos, embora mutações somáticas sejam raras, sua expressão encontra-se reduzida em cerca de $30 \%$ dos casos (Yoshikawa et al., 1999; Wilson et al., 1999), provavelmente por atuação de mecanismos epigenéticos. Esteller et al. (2000), relataram que a frequência de hipermetilação do BRCA1 varia nos diferentes subtipos histológicos e também naqueles que apresentam ou não LOH. Dos casos de carcinomas ductais $12 \%$ (9/73) estavam metilados, enquanto que os subtipos medular e mucinoso apresentaram 67 e 55\%, respectivamente, dos casos hipermetilados. Essa frequência foi ainda menor (5\%) nas amostras de carcinomas ductais sem LOH.

O gene BRCA1 está localizado no cromossomo 17q21, ele é composto por 24 exons que codificam uma proteína de 1863 aminoácidos. Classificado como supressor tumoral, sua função ainda não é totalmente conhecida (Miki et al., 1994). Sabe-se, porém, que sua proteína interage com outras que estão envolvidas na regulação do ciclo celular como a p53 (Zhang et al., 1998), no reparo do DNA como a Rad50 (Zhong et al., 1999), na transcrição como, por exemplo, a RNApolimerase II (Scully et al., 1997), no processamento do RNA como a RNA helicase A (Anderson et al., 1998), com o produto do gene BRCA2 (Chen et al., 1998) entre outras, sendo portanto associado à via de reparo e proliferação da carcinogênese mamária (Yoshikawa et al., 2000). Outra evidência de sua 
participação na carcinogênese mamária foi encontrada num estudo em que a introdução, in vitro, do gene normal BRCA1 em linhagem celular tumoral de mama e ovário inibiu o crescimento celular, o que não foi observado em linhagem tumoral de colon e pulmão (Holt et al., 1996).

\section{$1.6 h M L H 1$}

O gene $h M L H 1$, localizado no cromossomo 3p21.3, é um homólogo humano do gene de reparo da E. Coli e integrante do sistema de reparo de mal pareamento (MMR- mismatch repair) (NCBI, 2009). O MMR é fundamental para a estabilidade genômica, pois corrige, base por base, erros originados durante a replicação do DNA. O MMR melhora a fidelidade da síntese do DNA cerca de 100-1000 vezes, diminuindo a taxa de mutação global de um erro para cada 1010 nucleotídeos sintetizados (Modrich \& Lahue, 1996).

Alterações no mecanismo do MMR podem ter conseqüências drásticas no desenvolvimento da tumorigênese como o aumento na taxa de mutações, cerca de 100 vezes mais do que a observada em células normais (Thomas et al., 1996). Essas mutações são particularmente evidentes nas seqüências de microsatélites, que consiste em repetições de 1-4 pares de bases em regiões não codificantes. Instabilidade de microsatélites (MSI) é uma marca da deficiência do MMR em diversos tipos de cânceres (Thibodeau et al., 1993).

Em um grupo significante de tipos de tumores esporádicos MSI+, é rara a ocorrência de mutações nos genes do MMR (Thibodeau et al., 1996). Explicações alternativas para desregularão na função desses genes, durante o desenvolvimento desses cânceres, inclui processos epigenéticos como a hipermetilação da região promotora associada com a perda transcricional (Herman et al., 1995). Essa relação MSI+ e hipermetilação em genes do MMR como, por exemplo, o hMLH1, já está 
bem estabelecida nos tumores de cólon (Kane et al., 1997), de endométrio (Esteller et al., 1998) e gástrico (Fleisher et al., 1999), sendo ainda estudada no câncer de mama. Entretanto, Murata et al. (2002), relataram que a hipermetilação do $h M L H 1$ está fortemente associado (83.3\%) com a diminuição da expressão de sua proteína nos casos de câncer de mama MSI+. 


\section{Referências}

Agoston AT, Argani P, Yegnasubramanian S, De Marzo AM, Ansari-Lari MA, Hicks $\mathrm{JL}$, Davidson NE, Nelson WG. Increased protein stability causes DNA methyltransferase 1 dysregulation in breast cancer. J Biol Chem. 2005; 280: 18302-10.

Anderson SF, Schlegel BP, Nakajima T, Wolpin ES, Parvin JD. BRCA1 protein is linked to the RNA polymerase II holoenzyme complex via RNA helicase A. Nat Genet. 1998; 19: 254-56.

Balch C, Montgomery JS, Paik HI. New anti-cancer strategies: epigenetic therapies and biomarkers. Front Biosci. 2005; 10:1897-31.

Banerjee RV, Matthews RG. Cobalamin-dependent methionine synthase. J Faseb. 1990; 4: 1450-59.

Bast RC, Lilja H, Urban N, Rimm DL, Fritsche H, Gray HJ, Veltri R, Klee G, Allen A, Kim N, Gutman S, Rubin MA, Hruszkewycz A. Translational crossroads for biomarkers. Clin. Cancer Res. 2005; 11: 6103-08.

Baylin SB. DNA methylation and gene silencing in cancer. Nat Clin Pract. 2005; 2: 4-11.

Boushey CJ, Beresford SA, Omenn GS, Motulsky AG. A quantitative assessment of plasma homocysteine as a risk factor for vascular disease: probable benefits of increasing folic acid intakes. JAMA. 1995; 274: 104957.

Caldeira JRF, 2, Prando EC, Quevedo FC, Neto FAM, Rainho CA, Rogatto SR. CDH1 promoter hypermethylation and E-cadherin protein expression in infiltrating breast cancer. BMC Cancer. 2006; 6: 48- 57.

Chen J, Silver DP, Walpita D, Cantor SB, Gazdar, AF, Tomlinson G, Couch FJ, Weber BL, Aahley T, Livingston DM, Scully R. Stable interaction between the products of the BRCA1 and BRCA2 tumor suppressor genes in mitotic and meiotic cells. Mol Cell. 1998; 2: 317-28.

Chen T, Li E. Establishment and maintenance of DNA methylation patterns in mammals. Curr Top Microbiol Immunol. 2006; 301: 179-201.

Cianfrocca M, Goldstein LJ. Prognostic and predictive factors in early-stage breast câncer. The Oncologist. 2004; 9: 606-16.

Cleton-Jansen AM. E-cadherin and loss of heterozygosity at chromosome 16 in breast carcinogenesis: different genetic pathways in ductal and lobular breast cancer?. Breast Cancer Res. 2002; 4: 5-8.

Costello JF, Fruhwald MC, Smiraglia DJ, et al. Aberrant CpG-island methylation has non-random and tumour-type specific patterns. Nat Genet. 2000; 24: 132-38. 
Czeizel AE. Prevention of congenital abnormalities by periconceptional multivitamin supplementation. BMJ. 1993; 306: 1645-8.

Debbies MT, Welch DR. Genetic basis of human breast cancer metastasis. J Mam Gland Biol Neoplasia. 2001; 6: 441-5.

Dumitrescu RG, Cotarla I. Understanding breast cancer risk -where do we stand in 2005?. J. Cell. Mol. Med. 2005; 9: 208-21.

Duthie SJ. Folic acid deficiency and cancer: mechanisms of DNA instability. Br Med Bull. 1999; 55: 578-92.

Eads CA, Danenberg KD, Kawakami K, Saltz LB, Danenberg PV, Laird PW. CpG island hypermethylation in human colorectal tumors is not associated with DNA methyltransferase overexpression. Cancer Res. 1999; 59: 230206.

Esteller M, Corn PG, Baylin SB, Herman JG. A gene hypermethylation profile of human cancer. Cancer Res. 2001; 61: 3225-29.

Esteller M, Herman JG. Cancer as an epigenetic disease: DNA methylation and chromatin alterations in human tumors. J Pathol. 2002; 196: 1-7.

Esteller M, Levine R, Baylin SB, Ellenson LH, Herman JG. hMLH1 promoter hypermethylation is associated with the microsatellite instability phenotype in sporadic endometrial carcinomas. Oncogene. 1998; 17: 2413-17.

Esteller M, Silva JM, Dominguez G, Bonilla F, Matias-Guiu X, Lerma E, et al. Promoter hypermethylation and BRCA1 inactivation in sporadic breast and ovarian tumors. J Natl Cancer Inst. 2000; 92: 564-9.

Fleisher AS, Esteller M, Wang S. et al. Hypermethylation of the hMLH1 gene promoter in human gastric cancers with microsatellite instability. Cancer Res. 1999; 59: 1090-95.

Frixen UH, Behrens J, Sachs M, Eberle G, Voss B, Warda A, Lochner D, Birchmeier $W$. E-cadherin-mediated cell-cell adhesion prevents invasiveness of human carcinoma cells. J Cell Biol. 1991; 113: 173-85.

Frosst P, Blom HJ, Milos R, Goyette P, Sheppard CA, Matthews RG, Boers GJH, Hejer M, Klijtmans LAJ, Heuvel LP, Rozen RA. Candidate genetic risk factor for vascular disease: a common mutation in methylenetetrahydrofolate reductase. Nature Genetics. 1995; 10: 111-13.

Glynn SA, Albanes D. Folate and cancer: a review of the literature. Nutrition and Cancer. 1994; 22: 101-19.

Gopisetty G, Ramachandran K, Singal R. DNA methylation and apoptosis. Mol Immunol. 2006; 43: 1729-40. 
Goyette P, Sumner JS, Milos R, Duncan AM, Rosenblatt DS, Matthews RG, Rozen R. Human methylenetetrahydrofolate reductase: isolation of cDNA, mapping and mutation identification. Nat. Genet. 1994; 7: 195-200.

Graff JR, Herman JG, Lapidus RG, Chopra H, Xu R, Jarrard DF, Isaacs WB, Pitha $P M$, Davidson NE, Bavlin SB. E-cadherin expression is silenced by DNA hypermethylation in human breast and prostate carcinomas. Cancer Res. 1995; 55: 5195- 99.

Guilford P, Hopkins J, Harraway J, McLeod N, Harawira P, Taite H, Scoular R, Miller $A$, Reeve $A E$. E-cadherin germline mutations in familial gastric cancer. Nature. 1998; 392: 402-05.

Gumbiner BM. Regulation of cadherin adhesive activity. J Cell Biol. 2000; 148: 399-404.

Hennig G, Behrens J, Truss M, Frisch S, Reichmann E, Birchmeier W. Progression of carcinoma cells is associated with alterations in chromatin structure and factor binding at the E-cadherin promoter in vivo. Oncogene. 1995; 11: 475-84.

Herman JG, Merlo A, Mao L, Lapidus RG, Issa JP, Davidson NE, Sidransky D, Baylin SB. Inactivation of the CDKN2/p16/MTS1 gene is frequently associated with aberrant DNA methylation in all common human cancers. Câncer Res. 1995; 55: 4525-30.

Hirohashi S. Inactivation of the E-cadherin-mediated cell adhesion system in human cancers. Am J Pathol. 1998; 153: 333-39.

Holt JT, Thompson ME, Szabo C, Robinson-Benion C, Artega CL, King MC, Jensen RA. Growth retardation and tumor inhibition by BRCA1. Nature Genet. 1996; 12: 298-302.

Honorio S, Agathanggelou A, Schuermann M, Pankow W, Viacava P, Maher ER, Latif $F$. Detection of RASSF1A aberrant promoter hypermethylation in sputum from chronic smokers and ductal carcinoma in situ from breast cancer patients. Oncogene. 2003; 22: 147-50.

Horie N, Aiba H, Oguro K, Hojo H, Takeishi K. Functional analysis and DNA polymorphism of the tandemly repeated sequences in the 5'-terminal regulatory region of the human gene for thymidylate synthase. Cell Struct Funct. 1995; 20: 191-97.

INCA (Instituto Nacional do Câncer). Estimativa 2010: Incidência de câncer no Brasil. Disponível em: http://www.inca.gov.br. Acesso em 01 de dezembro de 2009.

INCA (Instituto Nacional do Câncer). TNM: classificação de tumores malignos. Disponível em: http://www.inca.gov.br. Acesso em 22 de julho de 2009.

Issa JP, Ottaviano $\mathrm{YL}$, Celano $\mathrm{P}$, Hamilton SR, Davidson NE, Baylin SB. Methylation of the oestrogen receptor $C p G$ island links aging and neoplasia in human colon. Nat Genet. 1994; 7: 536-40. 
Jacinto FV, Esteller M. Mutator pathways unleashed by epigenetic silencing in human câncer. Mutagenesis. 2007; 22: 247-53.

Jacob RA, Gretz DM, Taylor PC, James SJ, Pogribny IP, Miller BJ, Henning SM, Swendseid ME. Moderate folate depletion increases plasma homocysteine and decreases lymphocyte DNA methylation in postmenopausal women. J Nutr. 1998; 128: 1204-12.

Jaenisch R. DNA methylation and imprinting: why bother? Trends Genet. 1997; 13: 323-29.

Jones $\mathrm{PA}$, Baylin SB. The fundamental role of epigenetic events in cancer. Nat Rev Genet. 2002; 3: 415-28.

Kane MF, Loda M, Gaida GM, Lipman J, Mishra R, Goldman H, Jessup JM., Kolodner R. Methylation of the hMLH1 promoter correlates with lack of expression of hMLH1 in sporadic colon tumors and mismatch repairdefective human tumor cell lines. Cancer Res. 1997; 57: 808-11.

Key TJ, Verkasalo PK, Banks E. Epidemiology of breast cancer. The Lancet Oncology. 2001; 2: 133-40.

Laird PW, Jaenisch R. The role of DNA methylation in cancer genetic and epigenetic. Annu Rev Genet. 1996; 30: 441-64.

Leclerc D, Campeau E, Goyette P, Adjalla CE, Christensen B, Ross M, Eydoux P, Rosenblatt DS, Rozen R, Gravel RA. Human methionine synthase: cDNA cloning and identification of mutations in patients of the cbIG complementation group of folate/cobalamin disorders. Hum Mol Genet. 1996; 5:1867-74.

Mareel M, Bracke M, Van Roy F. Cancer Metastasis: Negative regulation by an Invasion Suppressor Complex. Cancer Detect Prev. 1995; 19: 451-64.

McPherson K, Steel CM, Dixon JM. Breast cancer: epidemiology, risk factors, and genetics. BMJ 2000; 321: 624-28.

Miki Y, Swensen J, Shattuck-Eidens D, Futreal PA, Harshman K, Tavtigian S, Liu $Q$, Cochran $C$, Bennett $L M$, Ding $W$, et al.. A strong candidate for the breast and ovarian câncer susceptibility gene BRCA1. Science. 1994; 266: 66-71.

Modrich $P$, Lahue $R$. Mismatch repair in replication fidelity, genetic recombination, and cancer biology. Annu. Rev. Biochem. 1996; 65: 101-133.

Murata $\mathrm{H}$, Khattar NH, Kang $\mathrm{Y}, \mathrm{Gu}$ L, Li $\mathrm{G}$. Genetic and epigenetic modification of mismatch repair genes hMSH2 and hMLH1 in sporadic breast cancer with microsatellite instability. Oncogene. 2002; 21: 5696 5703

Murphy N, Millar E, Lee CS. Gene expression profiling in breast cancer: towards individualising patient management. Pathology. 2005; 37: 271-7. 
NCBI (National Center for Biotechnology Information). Disponível em: http://www.ncbi.nlm.nih.gov. Acesso em 21 de setembro de 2009.

Overduin M, Harvey TS, Bagby S, Tong KI, Yau P, Takeichi M, Ikura M. Solution structure of the epithelial cadherin domain responsible for selective cell adhesion. Science. 1995; 267: 386-89.

Parkin DO. International variation. Oncogene. 2004; 23: 6329-40.

Patel A, Groopman JD, Umar A. DNA Methylation as a cancer specific biomarker from molecules to populations. Ann NY Acad of Sci. 2003; 983: 286-97.

Pogribny IP, Basnakian AG, Miller BJ, Lopatina NG, Poirier LA, James SJ. Breaks in genomic DNA and within the p53 gene are associated with they induce hypomethylation in livers of folate/methyl-deficient rats. Cancer Res. 1995; 55: 1894-901.

Rakha EA, Green AR, Powe DG, Roylance R, Ellis IO. Chromosome 16 tumorsuppressor genes in breast câncer. Genes, Chromossomes \& Câncer. 2006; 45: 527-35.

Ramsahoye BH, Biniszkiewicz D, Lyko F, Clark V, Bird AP, Jaenisch R. Non-CpG methylation is prevalent in embryonic stem cells and may be mediated by DNA methyltransferase 3a. Proc Natl Acad Sci U S A. 2000; 97: 5237-42.

Robertson KD, Ait-Si-Ali S, Yokochil T, Wade PA, Jones PL, Wolffe AP. DNMT1 forms a complex with Rb, E2F1, and HDAC1 and represses transcription from E2F-responsive promoters. Nat Genet. 2000; 25: 338-42.

Scully R, Anderson SF, Chao DM, Wei W, Ye L, Young R A, LivingstonI DM, Parvin JD. BRCA1 is a component of the RNA polymerase II holoenzyme. Proc Natl Acad Sci USA. 1997; 94: 5605-10.

Senti RF, Pilch SM. Analysis of folate data from the 2nd national health and nutrition Examination Survey (NHANES II). J Nutr. 1985; 115: 1398402.

Sharp $\mathrm{L}$, Little J. Polymorphisms in genes involved in folate metabolism and colorectal neoplasia: a HuGE review. Am J Epidemiol. $2004 ; 159(5): 423-43$.

Singal R, Ginder GD. DNA methylation. Blood. 1999; 93: 4059-70.

Srinivas PR, Kramer BS, Srivastava $S$. Trends in biomarker research for cancer detection. Lancet Oncol. 2001; 2: 698-704.

Suzuki T, Matsuo K, Hirose K, Hiraki A, Kawase T, Watanabe M, Yamashita T, Tajima HIK. One-carbon metabolism-related gene polymorphisms and risk of breast câncer. Carcinogenesis. 2008; 29: 356-62.

Thibodeau SN, Bren G, Schaid D. Microsatellite instability in cancer of the proximal colon. Science. 1993; 260: 816-819. 
Thibodeau SN, French AJ, Roche PC, Cunningham JM, Tester DJ, Lindor NM, Moslem G, Baker SM, Liskay MR, Burgart LJ, Honchel R, Halling KC. Altered expression of hMSH2 and hMLH1 in tumors with microsatellite instability and genetic alterations in mismatch repair genes. Cancer Res. 1996; 56: 4836-40.

Thomas DC, Umar A, Kunkel TA. Microsatellite instability and mismatch repair defects in cancer cells. Mutation Research. 1996; 350: 101-205.

Ulrich CM, Bigler J, Velicer CM, Greene EA, Farin FM, Potter JD. Searching Expressed Sequence Tag Databases: Discovery and Confirmation of a Common Polymorphism in the Thymidylate Synthase Gene. Cancer Epidemiology, Biomarkers \& Prevention. 2000; 9: 1381-85.

Watkins $D$, Rosenblatt DS. Functional methionine synthase deficiency (cb1E and cb1G): clinical and biochemical heterogeneity. Am J Med Genet. 1989; 34: 427-34.

Weisberg I, Tran P, Christensen B, Sibani S, Rozen R. A second genetic polymorphism in methylenetetrahydrofolate reductase (MTHFR) associated with decreased enzyme activity. Mol Genet Metab. 1998; 64: $169-72$.

Wilson CA, Ramos L, Villaseñor MR, Anders KH, Press MF, Clarke K, Karlan B, Chen JJ, Scully R, Livingston D, Zuch RH, Kanter $M H$, Cohen S, Calzone FJ, Slamon DJ. Localization of human BRCA1 and its loss in high- grade, non-inherited breast carcinomas. Nat. Genet. 1999; 21: 236-40.

Yoder BJ, Wilkinson EJ, Massoll NA. Molecular and morphologic distinctions between infiltrating ductal and lobular carcinoma of the breast. The Breast Journal. 2007; 13: 172-79.

Yoshikawa K, Honda K, Inamoto T, Shinohara H, Yamauchi A, Suga K, Okuyama T, Shimada T, Kodama H, Noguchi S, Gazdar AF, Yamaoka Y, Takahashi R. Reduction of BRCA1 protein expression in Japanese sporadic breast carcinomas and its frequent loss in BRCA1-associated cases. Clin. Cancer Res. 1999; 5: 1249-61.

Yoshikawak K, Ogawa T, Baer R, Hemmi H, Honda K, Yamauchi A, Inamoto T, Ko K, Yazumi S, Motoda H, Kodama H, Noguchi S, Gazdar AF, Yamaoka Y, Takahashi R. Abnormal expression of BRCA1 and BRCA1-interactive DNA repair proteins in breast carcinomas. Int J Cancer. 2000; 88: 28-36.

Zhang $H$, Somasundaram K, Peng $Y$, Tian $H$, Bi D, Weber BL, El-Deiry WS. BRCA1 physically associates with p53 and stimulates its transcriptional activity. Oncogene. 1998; 16: 1713-21.

Zhong Q, Chen CF, Li S, Chen Y,Wang CC, Xiao J, Chen PL, Sharp ZD, Lee WH. Association of BRCA1 with the hRad50- hMre11-p95 complex and the DNA damage response. Science. 1999; 285: 747-50. 


\title{
2. ARTIGO \\ Padrão de metilação dos genes CDH1, BRCA1, hMLH1 e polimorfismos das enzimas TS e MTHFR do ciclo do folato em tecido tumoral mamário
}

\author{
RESUMO
}

Mecanismos epigenéticos como a ativação e desativação de genes por meio da hipometilação e hipermetilação, respectivamente, da região promotora dos genes estão associados ao surgimento de diversos tipos de cânceres. Embora os fatores que resultam na metilação aberrante ainda não sejam bem conhecidos, a deficiência de folato têm sido associada a esse mecanismo no desenvolvimento de cânceres como de colo uterino, pulmão, mama, cólon e cérebro. Neste trabalho, foi avaliado se os polimorfismos em genes de enzimas chaves no metabolismo do folato como a timidilato sintase (TS) e metilenotetrahidrofolato redutase (MTHFR) influenciam o padrão de metilação da região promotora dos genes CDH1, BRCA1 e hMLH1 em amostras de carcinoma ductal invasivo. A metilação foi avaliada através da MS-PCR e os polimorfismos por PCR e PCR-RFLP. Não houve associação estatisticamente significante $(p<0.05$, teste exato de Fisher) do padrão de metilação dos genes $C D H 1$, BRCA1 e hMLH1 com estádio, grau histológico, idade e freqüência dos polimorfismos. O padrão de metilação da região promotora dos genes $C D H 1$, BRCA1 e $h M L H 1$, não foi alterada com a presença dos polimorfismos 5'UTR TS, C677T e A1298C MTHFR. Porém, o genótipo TT MTHFR juntamente com o genótipo 3R/3R da TS pareceu ter um papel protetor da metilação aberrante para o gene $B R C A 1$, embora não tenha sido estatisticamente significante.

Palavras chave: câncer de mama; metilação; polimorfismo MTHFR / TS; genes supressores. 


\section{INTRODUÇÃO}

O câncer de mama é o tipo de câncer mais comum entre as mulheres, correspondendo a $22 \%$ de todos os casos. Foram estimados mais de 1.050.000 casos novos de câncer de mama em todo o mundo no ano 2000 (1). No Brasil, sem considerar os tumores de pele não melanoma o câncer de mama é o mais incidente entre as mulheres, e para 2010 são esperados 49.240 casos novos e um risco estimado de 49 casos a cada 100 mil mulheres. Além disso, essa patologia constitui-se a primeira causa de morte por câncer entre as mulheres (2).

Mecanismos epigenéticos como metilação do DNA, deacetilação de histonas, ubiquitinação e fosforilação estão associados ao surgimento de diversos tipos de cânceres $(3,4)$, porém, o principal mecanismo epigenético ligado ao aparecimento de tumores é a ativação e desativação de genes por meio da hipometilação e hipermetilação, respectivamente, da região promotora dos genes (5).

Embora os fatores que resultam na metilação aberrante ainda não sejam bem conhecidos (6) a deficiência de folato têm sido associada a esse mecanismo na carcinogênese de colo uterino, pulmão, mama, cólon e cérebro (7). Portanto, polimorfismos em genes de enzimas chaves no metabolismo do folato como a timidilato sintase (TS) e metilenotetrahidrofolato redutase (MTHFR), também podem influenciar o risco para desenvolvimento de câncer (8).

A TS é uma enzima que catalisa a conversão da deoxiuridina monofosfato (dUMP) em deoxitimidina monofosfato (dTMP) usando o 5,10-metilenotetrahidrofolato como doador de radical metil (9). Ela é responsável pelo equilíbrio e oferta de nucleotídeos necessários para a replicação e reparo do DNA, sendo assim, essencial para a proliferação celular e também um importante alvo para as drogas anti câncer (10). Foi identificado um polimorfismo na região promotora $5^{\prime} U T R$ do TS, 
imediatamente acima do códon de iniciação ATG, que contém, normalmente, dupla ( $2 \mathrm{R}$ ) ou tripla ( $3 \mathrm{R}$ ) repetição de uma seqüência de 28 pb. Estudos in vitro e in vivo, mostraram que a expressão da TS é aumentada quando apresenta o alelo 3R (11). A MTHFR é uma importante enzima regulatória do metabolismo do folato. Ela catalisa a conversão do 5,10-metilenotetrahidrofolato em 5-metiltetrahidrofolato que é precursor da reação de metilação do DNA através da remetilação da homocisteína em metionina. Os polimorfismos mais comumente encontrados são MTHFR C677T e A1298C que estão associados a maior termolabilidade e considerável diminuição da atividade enzimática. Os homozigotos e os heterozigotos apresentam, in vitro, apenas 30\% e $60 \%$ da atividade enzimática, respectivamente $(12 ; 13)$.

O produto do gene $C D H 1$ é uma glicoproteína importante para a adesão celular, desenvolvimento e manutenção do fenótipo epitelial (14). A perda ou a baixa expressão da E-caderina tem sido amplamente documentada no câncer de mama, com a atuação de mecanismos genéticos e epigenéticos (15). O gene BRCA1 é um supressor tumoral e está intimamente relacionado com os casos hereditários do câncer de mama e ovário (16) e, embora mutações somáticas sejam raras nos casos esporádicos, sua expressão encontra-se reduzida em cerca de $30 \%$ dos casos provavelmente por atuação de mecanismos epigenéticos. $(17,18)$. 0 gene $h M L H 1$ é integrante do sistema de reparo de mal pareamento (MMRmismatch repair) (19). O MMR é fundamental para a estabilidade genômica, pois corrige, base por base, erros originados durante a replicação do DNA (20).

A determinação de biomarcadores de tumorogênese é útil na detecção precoce do câncer, no auxílio da previsão de risco do desenvolvimento tumoral e metástase, estratificação dos pacientes para o tratamento, além de ajudar na vigilância da recorrência da doença (21). 
Este trabalho avaliou os polimorfismos em genes de enzimas chaves no metabolismo do folato como a timidilato sintase (TS) e metilenotetrahidrofolato redutase $(M T H F R)$ e a influência destes no padrão de metilação da região promotora dos genes CDH1, BRCA1 e hMLH1, buscando sugerir biomarcadores de vias tumorigênicas do epitélio mamário.

\section{METODOLOGIA}

Para a realização deste trabalho foram analisadas 54 pacientes do sexo feminino, com diagnóstico de carcinoma ductal invasivo (CDI), com média de idade de 53,86 $\pm 14,3$ anos.

Todas as pacientes foram informadas sobre a pesquisa e assinaram o termo de consentimento livre e esclarecido.

As amostras de tecido tumoral foram obtidas no Hospital Assis Chateaubriand, Departamento de Patologia e Medicina Forense da cidade de Fortaleza-CE e as análises dos polimorfismos 5'UTR da TS, C677T e A1298C da MTHFR foram realizadas no Laboratório de Genética Molecular da Universidade Federal do Ceará, Fortaleza-CE.

A extração do DNA foi realizada a partir de tecido congelado, somente nos fragmentos que apresentaram mais do que $80 \%$ de células tumorais, usando cetiltrimetil amônio brometo (CTAB) adaptado do método descrito por Foster \& Twell (22). A presença e qualidade do DNA genômico foram monitoradas através de eletroforese em gel de agarose $1 \%$ corado com brometo de etídeo.

A análise de metilação das ilhas CpG foi realizada pelo tratamento com bissulfito de sódio seguido pela MS-PCR (Methylationspecific Polymerase Chain Reaction) (23) na qual um par de primers reconhece sequências metiladas $(M)$ e outro reconhece sequências não 
metiladas (U) (Tabela 1). Como controle positivo foi utilizado DNA extraído de leucócitos de voluntários saudáveis, tratados com a enzima CpG Metilase, conforme recomendação do fabricante (New England BioLabs).

Tabela 1. Seqüência dos primers utilizados na MS-PCR.

\begin{tabular}{|c|c|c|c|}
\hline Gene & Seqüência primer $\left(5^{\prime}-3^{\prime}\right)$ & Fragmento & Referência \\
\hline \multirow[t]{4}{*}{$C D H 1$} & M-TTAGGTTAGAGGGTTATCGCGT & $116 \mathrm{pb}$ & 23 \\
\hline & M-TAACTAAAAATTCACCTACCGAC & & \\
\hline & U-TAATTTTAGGTTAGAGGGTTATTGT & $97 \mathrm{pb}$ & \\
\hline & U-CACAACCAATCAACAACACA & & \\
\hline \multirow[t]{4}{*}{$B R C A 1$} & M-TCGTGGTAACGGAAAGCGC & $75 \mathrm{pb}$ & 24 \\
\hline & M-AAATCTCAACGAACTCACGCC & & \\
\hline & U-TTGGTTITTGTGGTAATGGAAAAGTGT & $86 \mathrm{pb}$ & \\
\hline & U-CAAAAAATCTCAACAAACTCACACCA & & \\
\hline \multirow[t]{4}{*}{ hMLH1 } & M-TATATCGTTCGTAGTATTCGTGT & $153 \mathrm{pb}$ & 25 \\
\hline & M-TCCGACCCGAATAAACCCAA & & \\
\hline & U-TITGATGTAGATGTIITATTAGGGTTGT & $124 \mathrm{pb}$ & \\
\hline & U-ACCACCTCATCATAACTACCCACA & & \\
\hline
\end{tabular}

As reações da MS-PCR foram realizadas com tampão $1 \times$ (Tris- $\mathrm{HCl}$ $20 \mathrm{mM}$ e $\mathrm{KCl} 50 \mathrm{Mm}) ; 1,5 \mathrm{mM} \mathrm{MgCl} 2 ; 0,2 \mathrm{mM}$ dNTP; $0,24 \mu \mathrm{M}$ de cada primer; 1,5U de Taq DNA Platinum (Invitrogen) e 50ng de DNA tratado com bissulfito de sódio, para um volume final de $25 \mu \mathrm{L}$. Os produtos amplificados foram visualizados em gel de poliacrilamida $6 \%$ não desnaturante, corado pelo nitrato de prata.

A avaliação do polimorfismo de repetição de $28 \mathrm{pb}$ da $T S$ utilizou a técnica de PCR nas condições descritas por Etienne et al. (26), exceto na adição de $10 \%$ dimetilsulfóxido (DMSO). Os primers usados foram 5' GTGGCTCCTGCGTTTCCCCC 3' sense e, 5' GCTCCGAGCCGGCCACAGGCA 3' antisense. Os fragmentos foram visualizados através de eletroforese em gel de poliacrilamida $6 \%$ corado pelo nitrato de prata e as bandas observadas foram de $220 \mathrm{pb}(2 \mathrm{R}), 248 \mathrm{pb}(3 \mathrm{R})$ ou ambas (2R/3R). 
A presença dos polimorfismos C677T e A1298C MTHFR foram avaliadas através da técnica de PCR-RFLP (Polymerase Chain Reaction Restriction Fragment Lenght Polymorphism) usando os primers 5' TGAAGGAGAAGGTGTCTGCGGGA 3' sense e 5' AGGACGGTGCGGTGAGAGTG 3' antisense e enzima de restrição Hinf I (13), e 5' AAGgAgGagctgctgaAgAtg $3^{\prime}$ sense e 5' CTTTGCCATGTCCACAGCATG 3' antisense seguida pela incubação coma enzima Mbo II (27), respectivamente. A visualização foi realizada pela eletroforese em gel de poliacrilamida $6 \%$ corado pelo nitrato de prata.

A anáilise estatística foi feita usando teste exato de Fisher através do software InStat 3, assumindo, para todos os testes, um valor estatísticamente significante $p<0,05$.

\section{RESULTADOS}

A média da idade das pacientes foi de $53,86 \pm 14,3$, variando entre $30-83$ anos.

Das 54 amostras de CDI estudadas, 49 amplificaram para o gene CDH1 sendo que $28(57,1 \%)$ eram metiladas e 21 (42,9\%) não metiladas. Para o gene BRCA1 53 amostras puderam ser analisadas, 2 (3,8\%) foram metiladas e $51(96,2 \%)$ não metiladas (Figura 1). Para o gene hMLH1 45 amostras foram amplificadas sendo que 8 (17,8\%) apresentaram metilação e $37(82,2 \%)$ não apresentaram metilaçao na região promotora do gene. Os dados de freqüência da metilação na região promotora dos genes estão sumarizados na tabela 2 . 


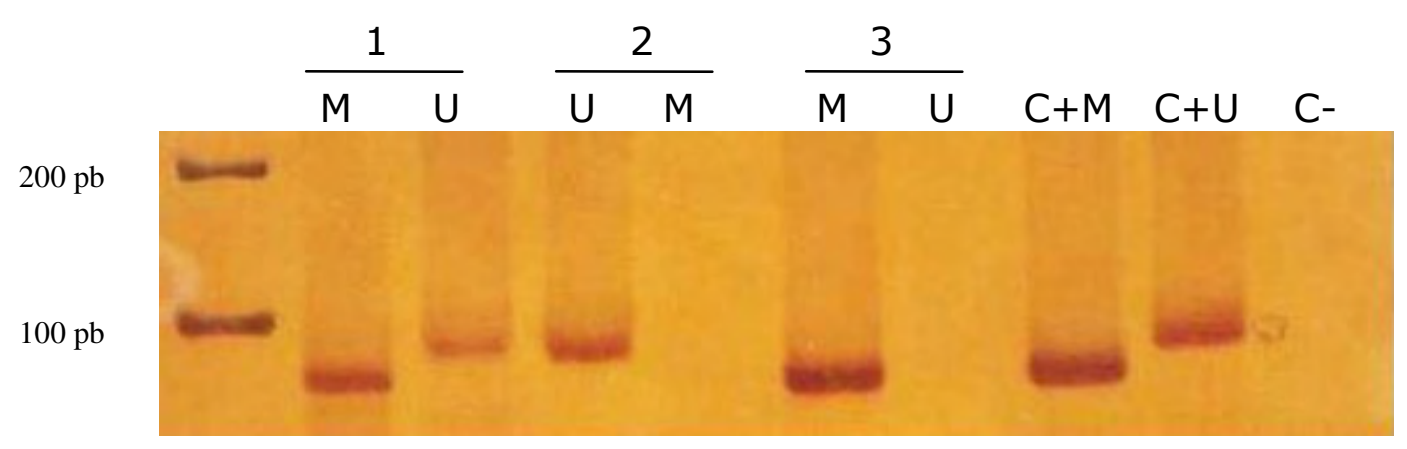

Figura 1. Resultado da análise de metilação do gene $B R C A 1$, feita por MSP PCR seguida por eletroforese em gel de poliacrilamida $6 \%$ corado por nitrato de prata.

Tabela 2. Padrão de metilação dos genes $C D H 1, B R C A 1, h M L H 1$.

\begin{tabular}{cccccc}
\hline \multicolumn{2}{c}{$C D H 1(\mathrm{n}=49)$} & \multicolumn{2}{c}{ BRCA1 $(\mathrm{n}=53)$} & \multicolumn{2}{c}{ hMLH1 $(\mathrm{n}=45)$} \\
\hline $\mathrm{U}(\%)$ & $\mathrm{M}(\%)$ & $\mathrm{U}(\%)$ & $\mathrm{M}(\%)$ & $\mathrm{U}(\%)$ & $\mathrm{M}(\%)$ \\
$21(42.9)$ & $28(57.1)$ & $51(96.2)$ & $2(3.8)$ & $37(82.2)$ & $8(17.8)$
\end{tabular}

$\mathrm{U}=$ não metilado $\mathrm{M}=$ metilado.

Com relação ao polimorfismo da TS, 12 amostras (22,2\%) eram 2R/2R, $18(33,3 \%)$ 2R/3R e $24(44,5 \%)$ apresentaram genótipo 3R/3R. Das 54 amostras, $24(44,4 \%)$ apresentaram alelo selvagem CC para C677T da MTHFR, $20(37,1 \%)$ eram heterozigotos CT e $10(18,5 \%)$ eram TT. Para o polimorfismo A1298C da MTHFR, 53 amostras amplificaram, sendo $32(60,4 \%)$ AA, $19(35,8 \%)$ AC e $2(3.8 \%)$ CC, dados sumarizados na Tabela 3. 
Tabela3. Freqüência dos polimorfismos 5 'UTR TS, C677T e A1298C do MTHFR em amostras de carcinoma ductal invasivo.

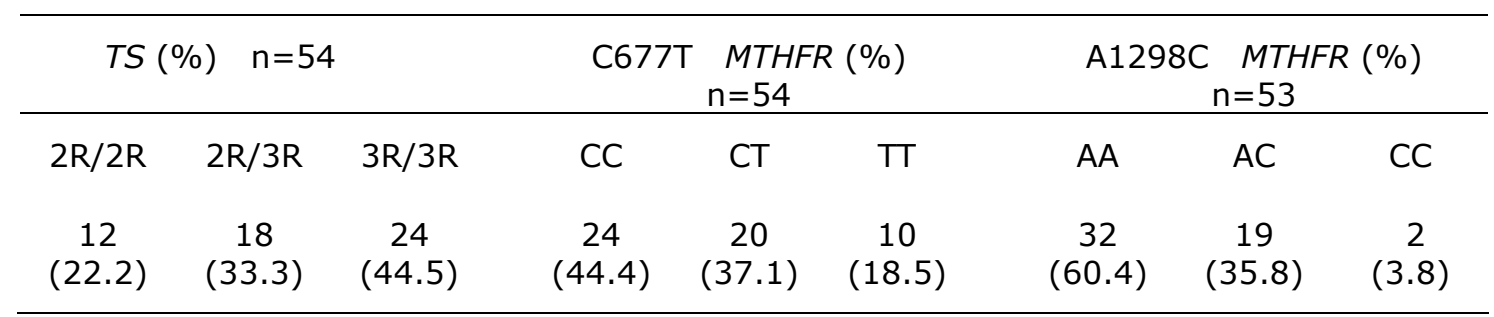

$\mathrm{TS}=$ timidilato sintase; MTHFR= metilenotetrahidrofolato redutase.

A tabela 4 apresenta a associação do padrão de metilação com parâmetros clínicos das amostras de CDI. Não foi encontrada diferença estatisticamente significante entre o padrão metilado e não metilado, dos genes CDH1, BRCA1 e hMLH1, quando associados com estádio, grau histológico e idade das pacientes.

Tabela 4. Distribuição do padrão de metilação dos genes $C D H 1, B R C A 1, h M L H 1$ de acordo com o estádio, grau histológico e idade de pacientes com carcinoma ductal invasivo.

\begin{tabular}{|c|c|c|c|c|c|c|c|c|c|}
\hline & \multicolumn{2}{|c|}{$\mathrm{CDH} 1$} & & \multicolumn{2}{|c|}{$B R C A 1$} & \multicolumn{4}{|c|}{ hMLH1 } \\
\hline & U (\%) & M (\%) & & U (\%) & M (\%) & & U (\%) & M (\%) & \\
\hline \multicolumn{10}{|c|}{ Estádio } \\
\hline I / II & $12(50)$ & $12(50)$ & $P=0.353$ & $26(100)$ & $0(0)$ & $P=0.435$ & $19(82.6)$ & $4(17.4)$ & $P=0.693$ \\
\hline III & $6(33.3)$ & $12(66.7)$ & & $19(95)$ & $1(5)$ & & $12(75)$ & $4(25)$ & \\
\hline \multicolumn{10}{|c|}{ Grau Histológico } \\
\hline I / II & $5(35.7)$ & $9(64.3)$ & $P=0.495$ & $14(100)$ & 0 & $P=0.516$ & $11(84.6)$ & $2(15.4)$ & $P=1.000$ \\
\hline III & $10(50)$ & $10(50)$ & & $21(91.3)$ & $2(8.7)$ & & $17(85)$ & $3(15)$ & \\
\hline \multicolumn{10}{|c|}{ Idade (anos) } \\
\hline$\geq 45$ & $13(38.2)$ & $21(61.8)$ & $P=0.176$ & $34(94.4)$ & $2(5.6)$ & $P=1.000$ & $23(82.1)$ & 5 (17.9) & $P=1.000$ \\
\hline$<45$ & $7(63.6)$ & $4(36.4)$ & & $13(100)$ & 0 & & $12(85.7)$ & $2(14.3)$ & \\
\hline
\end{tabular}

$U=$ não metilado; $M=$ metilado.

Teste exato de Fisher com IC 95\%. 
A associação do padrão de metilação da região promotora dos genes $C D H 1, B R C A 1, h M L H 1$ com os genótipos 2R/2R, 2R/3R, 3R/3R do gene TS; CC, CT e TT (677) e AA, AC e CC (1298) do MTHFR estão sumarizados na tabela 5. Quando avaliada a associação desse mesmo padrão de metilação com os polimorfismos das enzimas TS e MTHFR conjuntamente, não foi encontrada associação significativa ( $p>0.05)$ (dados não apresentados).

Tabela 5. Associação do padrão de metilação dos genes $C D H 1, B R C A 1, h M L H 1$ de acordo com os polimorfismos TS e MTHFR.

\begin{tabular}{|c|c|c|c|c|c|c|c|c|c|}
\hline & \multicolumn{3}{|c|}{$\mathrm{CDH1}$} & \multicolumn{2}{|c|}{$B R C A 1$} & \multicolumn{4}{|c|}{$h M L H 1$} \\
\hline & U (\%) & M (\%) & & U (\%) & M (\%) & & U (\%) & M (\%) & \\
\hline TS & & & & & & & & & \\
\hline $2 \mathrm{R} / 2 \mathrm{R}$ & $5(41.6)$ & $7(58.4)$ & $P=0.995$ & $10(90.9)$ & $1(9.1)$ & $P=0.377$ & $8(80)$ & $2(20)$ & $P=0.520$ \\
\hline $2 R / 3 R$ & $6(42.8)$ & $8(57.2)$ & & $17(94.4)$ & $1(5.6)$ & & $12(92.3)$ & $1(7.7)$ & \\
\hline $3 R / 3 R$ & $10(43.4)$ & $13(56.6)$ & & $24(100)$ & 0 & & $17(72.2)$ & $5(27.8)$ & \\
\hline \multicolumn{10}{|c|}{ C677T MTHFR } \\
\hline $\mathrm{CC}$ & $7(31.8)$ & $15(68.2)$ & $P=0.299$ & $23(95.8)$ & $1(4.2)$ & $P=0.771$ & $19(90.4)$ & $2(9.6)$ & $P=0.283$ \\
\hline $\mathrm{CT}$ & $8(47)$ & $9(53)$ & & $18(94.7)$ & $1(5.3)$ & & $12(80)$ & $3(20)$ & \\
\hline$\pi$ & $6(60)$ & $4(40)$ & & $10(100)$ & 0 & & $6(66.6)$ & $3(33.4)$ & \\
\hline \multicolumn{10}{|c|}{ A1298C MTHFR } \\
\hline AA & $13(46.4)$ & $15(53.6)$ & $P=0.849$ & $29(93.5)$ & $2(6.5)$ & $P=0.262$ & $21(84)$ & $4(16)$ & $P=0.903$ \\
\hline$A C$ & $6(33.3)$ & $12(66.7)$ & & $19(100)$ & 0 & & $13(76.5)$ & $4(23.5)$ & \\
\hline $\mathrm{CC}$ & $2(100)$ & 0 & & $2(100)$ & 0 & & $2(100)$ & 0 & \\
\hline
\end{tabular}

$\mathrm{U}=$ não metilado; $\mathrm{M}=$ metilado; $\mathrm{TS}=$ timidilato sintase $; \mathrm{MTHFR}=$ metilenotetrahidrofolato redutase.

Teste exato de Fisher com IC 95\%. 


\section{DISCUSSÃO}

Neste trabalho foi avaliada a associação do padrão de metilação dos genes $C D H 1, B R C A 1, h M L H 1$ com estádio, grau histológico, idade das pacientes e polimorfismos de enzimas do ciclo do folato (TS e MTHFR) em 54 amostras de carcinoma ductal invasivo.

É sabido que o $C D H 1$ é um dos genes mais freqüentemente inativado pela metilação nos casos de câncer esporádico (28) e que essa frequência aumenta substancialmente com o progresso da doença, o que foi consistente com nossos resultados. Neste mesmo sentido, outros estudos mostraram que a metilação do $C D H 1$ no câncer de mama é heterogênea e está presente em todos os estádios com uma tendência a aumentar nos estádios tardios e em metástase $(29,30)$ o que faz sentido se levarmos em conta sua função de manutenção do fenótipo epitelial. Concordando com nossos resultados, Caldeira et al. observaram $72 \%$ das amostras hipermetiladas para o $C D H 1$, entretanto, também não encontraram associação estatisticamente significante com estádio, grau histológico e idade das pacientes (31) sugerindo que a mudança do padrão de metilação não tenha sido relacionada à idade mas por desregulação da atividade da metiltransferase durante a progressão do tumor (32).

Vários mecanismos podem estar envolvidos na baixa expressão do BRCA1 no câncer de mama, entretanto, uma possível explicação para a pequena taxa de metilação observada, independente do estádio, poderia ser dada pela análise de LOH (perda de heterozigose). Esteller et al., descreveram que a freqüência de metilação no BRCA1 é de $5 \%$ em CDI sem LOH enquanto os CDI que apresentam LOH está freqüência é de $20 \%$. Comparando com subtipos histológicos específicos como o mucinoso e o medular, também encontrou uma menor freqüência de metilação aberrante do BRCA1 nos CDI (24). 
O silenciamento de genes supressores de tumor, pela hipermetilação da região promotora, é um evento comum e aparentemente precoce na carcinogênese, conferindo à célula tumoral vantagem seletiva de crescimento e instabilidade genética (33). Entretanto, Naqvi et al. encontraram forte associação $(P<.0001)$ entre o hMLH1 não metilado com estádio precoce do tumor, indicando que a metilação deste gene é um evento tardio no câncer de mama (34). Embora não tenha sido estatisticamente significante, provavelmente pelo número reduzido de amostras, nossos resultados demonstram uma tendência para essa mesma associação, sugerindo que o padrão de metilação do $h M L H 1$ não seja um bom biomarcador para esse tipo de tumor.

A diminuição global de 5 metilcitosina e hipermetilação aberrante em loci específicos, são eventos esperados durante o envelhecimento celular e associados à carcinogênese (35). Embora no presente estudo a associação da idade com hipermetilação não tenha sido estatisticamente significante em nenhum dos genes estudados, a grande maioria, $61.8 \%$ e $100 \%$, das amostras metiladas, foram de pacientes com idade $\geq 45$ anos para o CDH1 e BRCA1, respectivamente. No caso do $h M L H 1$, esta tendência não pôde ser observada. Poderia ser especulado que este gene esteja "protegido" do processo de metilação aberrante provavelmente pela sua função de manutenção da estabilidade genética, fundamental para a sobrevivência da célula.

Vários estudos têm sido publicados investigando a associação entre polimorfismos em enzimas do ciclo do folato com metilação aberrante no promotor de genes em diversos tipos de tumores, porém, com resultados inconsistentes. Neste trabalho, não houve associação estatisticamente significante, entre o padrão de metilação dos genes $C D H 1, B R C A 1$ e $h M L H 1$ e os polimorfismos das enzimas TS e MTHFR.

Com relação a TS, Zhai et al., fizeram uma análise com estudo caso-controle, $n=432$ e $n=473$ respectivamente, de suscetibilidade ao 
câncer de mama na presença dos polimorfismos 5'UTR TS e também não encontraram resultados estatisticamente significantes (36). Embora estudos de associações do polimorfismo da TS e metilação aberrante não tenham sido encontrados, já se sabe que esse polimorfismo está relacionado com uma maior sensibilidade ao agente quimioterápico 5fluoracil (37), reforçando a idéia que suas variantes têm um papel importante na biologia do tumor de mama.

Corroborando nosso trabalho, os polimorfismos no gene da MTHFR não foram associados com a hipermetilação da região promotora em cânceres coloretal (38), cervical (39) e esofágico (40).

No câncer de mama, especificamente, poucos trabalhos têm feito essa associação. Li et al., investigaram se polimorfismos em enzimas do folato, entre eles o MTHFR C677T, estavam associados com a metilação da região promotora de sete genes, incluindo o CDH1. Em 227 casos de câncer de mama e, concordando com nossos resultados, não observaram nenhuma associação (41). Tao et al., também não encontraram nenhuma associação entre os polimorfismos MTHFR e MS (metionina sintase) com metilação aberrante nos genes $C D H 1, p 16, R A R-\beta_{2}$ em 803 tumores de mama (42). Neste trabalho, o que pôde ser observado, foi que a presença do genótipo TT do polimorfismo T677T da MTHFR juntamente com o genótipo $3 R / 3 R$ da $T S$ pareceu ter um papel protetor para metilação aberrante no gene $B R C A 1$, provavelmente pela diminuição da atividade enzimática da MTHFR e aumento da atividade da TS. 
CONCLUSÃO

Os fatores que resultam na metilação aberrante ainda não são bem conhecidos. Entretanto, a deficiência de folato tem sido associada a esse mecanismo $(6,7)$. Portanto, polimorfismos em genes de enzimas chaves no metabolismo do folato como a TS e MTHFR, poderiam influenciar a manutenção da via de metilação.

Não houve associação estatisticamente significante da hipermetilação dos genes $C D H 1, B R C A 1$ e $h M L H 1$ com estadiamento, grau histológico e idade das pacientes.

O padrão de metilação da região promotora dos genes $C D H 1$, BRCA1 e $h M L H 1$, não foi alterada com a presença dos polimorfismos 5'UTR TS, C677T e A1298C MTHFR. Porém, o genótipo TT MTHFR juntamente com o genótipo $3 R / 3 R$ da $T S$ pareceu sugerir um papel protetor da metilação aberrante para o gene $B R C A 1$, embora não tenha sido estatisticamente significante.

Estudos com número maior de amostras, que inclua outras enzimas importantes do ciclo do folato como, por exemplo, a MS e que avalie a ingestão de folato na dieta são necessários para obter resultados mais consistentes. 


\section{Referências}

1. Parkin DO. International variation. Oncogene. $2004 ; 23: 6329-40$.

2. INCA (Instituto Nacional do Câncer). Estimativa 2010: Incidência de câncer no Brasil. Disponível em: http://www.inca.gov.br. Acesso em 01 dezembro de 2009.

3. Feinberg AP. The epigenetics of câncer etiology. Seminars in cancer biology. 2004; 14: 427-32.

4. Kim YI. Nutritional epigenetics: impact of folate deficiency on DNA methylation and colon cancer susceptibility. J Nutr. 2005; 135: 2703-09.

5. Sugimura T, Ushijima $T$. Genetic and epigenetic alterations in carcinogenesis. Mutation Research. 2000; 426: 235-46.

6. Choi SW, Mason JB. Folate status: effects on pathways of colorectal carcinogenesis. J Nutr. 2002; 132: 2413 - 8S.

7. Duthie SJ. Folic acid deficiency and cancer: mechanisms of DNA instability. Br Med Bull. 1999; 55: 578-92.

8. Goyette P, Sumner JS, Milos R, Duncan AM, Rosenblatt DS, Matthews RG, Rozen R. Human methylenetetrahydrofolate reductase: isolation of cDNA, mapping and mutation identification. Nat. Genet. 1994; 7: 195-200.

9. Sharp L, Little J. Polymorphisms in genes involved in folate metabolism and colorectal neoplasia: a HuGE review. Am J Epidemiol. $2004 ; 159(5): 423-43$.

10. Ulrich CM, Bigler J, Velicer CM, Greene EA, Farin FM, Potter JD. Searching Expressed Sequence Tag Databases: Discovery and Confirmation of a Common Polymorphism in the Thymidylate Synthase Gene. Cancer Epidemiology, Biomarkers \& Prevention. 2000; 9: 1381-85.

11. Horie $N$, Aiba $H$, Oguro $K$, Hojo $H$, Takeishi $K$. Functional analysis and DNA polymorphism of the tandemly repeated sequences in the 5'terminal regulatory region of the human gene for thymidylate synthase. Cell Struct Funct. 1995; 20: 191-97.

12. Frosst $P$, Blom $H J$, Milos $R$, Goyette $P$, Sheppard CA, Matthews RG, Boers GJ, den Heijer $M$, Kluijtmans LA, van den Heuvel LP, et al. A candidate genetic risk factor for vascular disease: a common mutation in methylenetetrahydrofolate reductase. Nat Genet. 1995; 10: 111-3.

13. Weisberg I, Tran $P$, Christensen $B$, Sibani $S$, Rozen R. A second genetic polymorphism in methylenetetrahydrofolate reductase (MTHFR) associated with decreased enzyme activity. Mol Genet Metab. 1998; 64: $169-72$.

14. Overduin $M$, Harvey TS, Bagby $S$, Tong $K I$, Yau $P$, Takeichi $M$, Ikura $M$. Solution structure of the epithelial cadherin domain responsible for selective cell adhesion. Science. 1995; 267: 386-89. 
15. Cleton-Jansen AM. E-cadherin and loss of heterozygosity at chromosome 16 in breast carcinogenesis: different genetic pathways in ductal and lobular breast cancer?. Breast Cancer Res. 2002; 4: 5-8.

16. Miki $Y$, Swensen J, Shattuck-Eidens D, Futreal PA, Harshman K, Tavtigian $S$, Liu Q, Cochran C, Bennett LM, Ding W, et al.. A strong candidate for the breast and ovarian câncer susceptibility gene BRCA1. Science. 1994; 266: $66-71$.

17. Yoshikawa $K$, Honda $K$, Inamoto $T$, Shinohara $H$, Yamauchi $A$, Suga $K$, Okuyama T, Shimada T, Kodama H, Noguchi S, Gazdar AF, Yamaoka Y, Takahashi R. Reduction of BRCA1 protein expression in Japanese sporadic breast carcinomas and its frequent loss in BRCA1-associated cases. Clin. Cancer Res. 1999; 5: 1249-61.

18. Wilson $C A$, Ramos $L$, Villaseñor $M R$, Anders $K H$, Press $M F$, Clarke $K$, Karlan $B$, Chen JJ, Scully R, Livingston D, Zuch RH, Kanter $M H$, Cohen S, Calzone FJ, Slamon DJ. Localization of human BRCA1 and its loss in high- grade, non-inherited breast carcinomas. Nat. Genet. 1999; 21: 236-40.

19. NCBI (National Center for Biotechnology Information). Disponível em: http://www.ncbi.nIm.nih.gov. Acesso em 21 de setembro de 2009.

20. Modrich $P$, Lahue $R$. Mismatch repair in replication fidelity, genetic recombination, and cancer biology. Annu. Rev. Biochem. 1996; 65: 101-133.

21. Bast RC, Lilja $H$, Urban $N$, Rimm $D L$, Fritsche $H$, Gray $H J$, Veltri $R$, Klee $G$, Allen A, Kim N, Gutman S, Rubin MA, Hruszkewycz A. Translational crossroads for biomarkers. Clin. Cancer Res. 2005; 11: 6103-08.

22. Foster GD, Twell D. Plant gene isolation: principles and practice. Plant genetics and breeding. 1996.

23. Herman JG, Graff JR, Myohanen S, Nelkin BD, Baylin S. Methylationspecific PCR: A novel PCR assay for methylation status of CpG islands. Medical Sciences. 1996; 93: 9821-26.

24. Esteller M, Silva JM, Dominguez G, Bonilla F, Matias-Guiu X, Lerma $E$, et al. Promoter hypermethylation and BRCA1 inactivation in sporadic breast and ovarian tumors. J Natl Cancer Inst. 2000; 92: 564-9.

25. Kang $\mathrm{GH}$, him $\mathrm{YH}$, Jung $\mathrm{HY}$, Kim WH, Ro JY, Rhyu M. CpG Island Methylation in Premalignant Stages of Gastric Carcinoma. 2001; 61: 284751.

26. Etienne $M$, Chazal $M$, Laurent-Puig $P$, Magne $N$, Rosty C, Formento J, Francoual M, Formento P, Rene N, Chamorey E, Bourgeon A, Seitz J, Delpero J, Letoublon C, Pezet D, Milano G. Prognostic value of tumoral thymidylate synthase and p53 in metastatic colorectal cancer patients receiving fluorouracil-based chemotherapy: phenotypic and genotypic analyses. Journal of Clinical Oncology. 2002; 20: 2832-43. 
27. Cicek MS, Nock NL, Li L, Conti DV, Casey G, Witte S. Relationship between methylenetetrahydrofolate reductase C667T and A1298C genotypes and haplotypes and prostate cancer risk and aggressiveness. Cancer Epidemiol Biomarkers Prev. 2004; 13: 1331-6.

28. Parrela $P$, Poeta $M L$, Gallo $A P$, Prencipe $M$, Scintu $M$, Apicella $A$, Rossielo $R$, Liguoro G, Seripa D, Gravina C, Rabitti C, Rinaldi M, Nicol T, Tommasi S, Paradiso A, Schittulli F, Altomare V, Fazio VM. Nonrandom distribution of aberrant promoter methylation of cancer-related genes in sporadic breast tumors. Clin Cancer Res. 2004; 10:5349-54.

29. Nass SJ, Herman JG, Gabrielson E, Iversen PW, Parl FF, Davidson NE, Graff JR. Aberrant methylation of the estrogen receptor and E-Cadherin $5^{\prime \prime}$ CpG islands increases with malignant progression in human breast cancer. Cancer Research. 2000; 60: 4346-48.

30. Graff JR, Gabrielson E, Fujii H, Baylin SB, Herman JG. Methylation patterns of the E-cadherin $5^{\prime}$ CpG island are unstable and reflect the dynamic, heterogeneous loss of E-cadherin expression during metastatic progression. J Biol Chem. 2000; 275: 2727-32.

31. Caldeira JRF, 2, Prando EC, Quevedo FC, Neto FAM, Rainho CA, Rogatto SR. CDH1 promoter hypermethylation and E-cadherin protein expression in infiltrating breast cancer. BMC Cancer. 2006; 6: 48- 57.

32. De Marzo AM, Marchi VL, Yang ES, Veeraswamy $R$, Lin $X$, Nelson WG. Abnormal regulation of DNA methyltransferase expression during colorectal carcinogenesis. Cancer Res. 1999; 59:3855-60.

33. Jones $P A$, Baylin $S B$. The fundamental role of epigenetic events in cancer. Nat Rev Genet. 2002; 415-28.

34. Naqvi RA, Hussain $A$, Deo SSV, Kukreti $H$, Chauhan $M$, Sarin $R$, Saxena $A$, Asim M, Shukla NK, MSb, Husain SA, Pasha ST, Basir SF. Hypermethylation analysis of mismatch repair genes (hmlh1 and hmsh2) in locally advanced breast cancers in Indian women. Human Pathology. 2008; 39: 672-80.

35. Calvanese $V$, aLara $E$, Kahn $A$, Fraga MF. The role of epigenetics in aging and age-related diseases. Ageing Research Reviews; 2009 8: 268-76.

36. Zhai X, Gao J, Hu Z, Tang J, Qin J, Wang S, Wang X, Jin G, Liu J, Chen W, Chen $F$, Wang $X$, Wei $Q$, Shen $H$. Polymorphisms in thymidylate synthase gene and susceptibility to breast cancer in a Chinese population: a casecontrol analysis. BMC Cancer. 2006; 6: 138-145.

37. Etienne $M C$, Formento $\mathrm{JL}$, Laurent-Puig $\mathrm{P}$, Formento $\mathrm{P}$, Cheradame $\mathrm{S}$, Fischel1 JL, Milano G. Thymidylate synthase and methylenetetrahydrofolate reductase gene polymorphisms: relationships with 5-fluorouracil sensitivity. British J Cancer. 2004; 90: 526-34. 
38. Clarizia $A D$, Bastos-Rodrigues $L$, Pena $H B$, Anacleto $C$, Rossi $B$, Soares $F A$, Lopes A, Rocha JC, Caballero O, Camargo A, Simpson AJ, Pena SD. Relationship of the methylenetetrahydrofolate reductase $C 677 \mathrm{~T}$ polymorphism with microsatellite instability and promoter hypermethylation in sporadic colorectal cancer. Genet Mol Res. 2006; 5:315 - 22.

39. Kang S, Kim JW, Kang GH, Park NH, Song YS, Kang SB, Lee HP. Polymorphism in folate- and methionine-metabolizing enzyme and aberrant CpG island hypermethylation in uterine cervical cancer. Gynecol Oncol. 2005; 96: $173-80$.

40. Wang J, Sasco AJ, Fu C, Xue H, Guo G, Hua Z, Zhou Q, Jiang Q, Xu B. Aberrant DNA methylation of P16, MGMT, and hMLH1 genes in combination with MTHFR C677T genetic polymorphism in esophageal squamous cell carcinoma. Cancer Epidemiol Biomarkers Prev. 2008; 17:11825.

41. Li SY, Rong $M$, Iacopetta B. Germ-line variants in methyl-group metabolism genes and susceptibility to DNA methylation in human breast cancer. Oncol Rep. 2006; 15: $221-5$.

42. Tao MH, Shields PG, Nie J, Marian $C$, Ambrosone CB, McCann SE, Platek M, Krshnan SS, Xie B, Edge SB, Winston J, Vito D, Trevisan M, Freudenheim JL. DNA Promoter Methylation in Breast Tumors: No Association with Genetic Polymorphisms in MTHFR and MTR. Cancer Epidemiol Biomarkers Prev. 2009; 18: 998-1002. 


\section{ANEXOS}

\section{TERMO DE CONSENTIMENTO DO PACIENTE}

Instituição: Universidade Federal do Ceará

Departamento de Patologia e Medicina Forense

Laboratório de Genética Molecular

Endereço: R. Coronel Nunes de Melo, 1127 Porangabuçu

Pesquisador Responsável: Silvia Helena Barem Rabenhorst

Título: Polimorfismos de enzimas do ciclo do folato em câncer de mama: risco e resposta terapêutica a 5-fluorouracil e metotrexato

$\mathrm{Eu}$, por este meio, fui informado (a), em detalhes, sobre o estudo intitulado "Polimorfismos de enzimas do ciclo do folato em câncer de mama: risco e resposta terapêutica a 5-fluorouracil e metotrexato".

Eu serei um dos participantes deste estudo em diversas instituições.

O estudo em questão pretende associar fatores genéticos de risco, que podem levar ao desenvolvimento do câncer de mama, e o padrão de sensibilidade deste tumor aos quimioterápicos mais usados, de modo a efetuar medidas preventivas e obter o máximo de benefícios para o paciente. Eu compreendo que minha participação é inteiramente voluntária.

Todos os dados da minha participação neste estudo serão documentados e mantidos confidencialmente, sendo disponível apenas para as autoridades de saúde e profissionais envolvidos neste estudo, os quais, quando necessário, terão acesso ao meu prontuário.

Como minha participação é voluntária, posso abandonar o estudo a qualquer momento, sem que resulte em qualquer penalidade ou perda de meus direitos onde recebo atendimento médico.

Se eu tiver qualquer dúvida ou perguntas relativas a este estudo ou aos meus direitos no que diz respeito a minha participação, posso entrar em contato com Raquel no telefone 91812556 ou Dra. Sílvia Helena no telefone 99945689.

Assinatura do paciente:

Data: / /

Endereço e telefone do paciente:

Nome da testemunha:

Assinatura da testemunha:

Data: / /

Assinatura do investigador: 


\section{Unesiversidade Estadual Paulista Faculdade de Medicina de Botucatu}

Distrito Rubião Junior, $s / n^{\circ}$ - Botucatu - S.P.

CEP: 18.618-970

Fone/Fax: (0xx14) 3811-6143

e-mail secretaria: capellup@fmb.unesp.br

Ilustríssima Senhora

Prof ${ }^{a} D r^{a}$ Maria Inês de Moura Campos Pardini

Divisão de Hemocentro da

Faculdade de Medicina de Botucatu.

Prezada Dra Maria Inês,

De ordem do Senhor Coordenador deste CEP, informo que o Projeto de Pesquisa "Metilação e polimorfismos em câncer de mama", a ser conduzido por Chiara de Campos Legnaro, orientada por Vossa Senhoria, com a colaboração das Dras Silvia Helena Barem Rabenhorst e Adriana Camargo Ferrasi, recebeu do relator parecer favorável, aprovado em reunião de 02/06/08. Não é necessário o envio à CONEP haja vista cumprir aos termos da Resolução 340/2004.

Situação do Projeto: APROVADO. Ao final da execução deste Projeto, apresentar ao CEP "Relatório Final de Atividades".

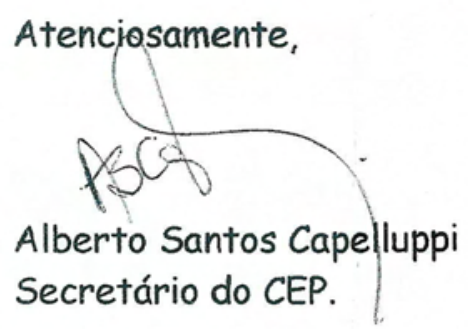




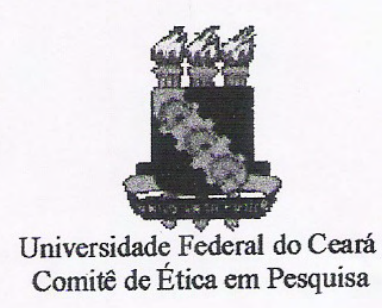

Of. $\mathbf{N}^{\circ} 649 / 05$

Fortaleza, 23 de setembro de 2005

Protocolo COMEPE n $^{0}$ 306/04

Pesquisador responsável: Silvia Helena Barem Rabenhorst

Dept $^{\circ}$./Serviço: Departamento de Patologia e Medicina Legal/UFC

Título do Projeto: "Polimorfismo de enzimas do ciclo do folato em câncer de mama: risco e resposta terapêtica a 5-fluorouracil e metotrexato"

Levamos ao conhecimento de V.S . que o Comitê de Ética em Pesquisa e do Complexo Hospitalar da Universidade Federal do Ceará - COMEPE, dentro das normas que regulamentam a pesquisa em seres humanos, do Conselho Nacional de Saúde - Ministério da Saúde, Resolução nº196 de 10 de outubro de 1996 e Resolução no 251 de 07 de agosto de 1997, publicadas no Diário Oficial, em 16 de outubro de 1996 e 23 de setembro de 1997, respectivamente, aprovou o projeto supracitado na reunião do dia 22 de setembro de 2005.

Outrossim, informamos, que o pesquisador deverá se comprometer a enviar o relatório parcial e final do referido projeto.

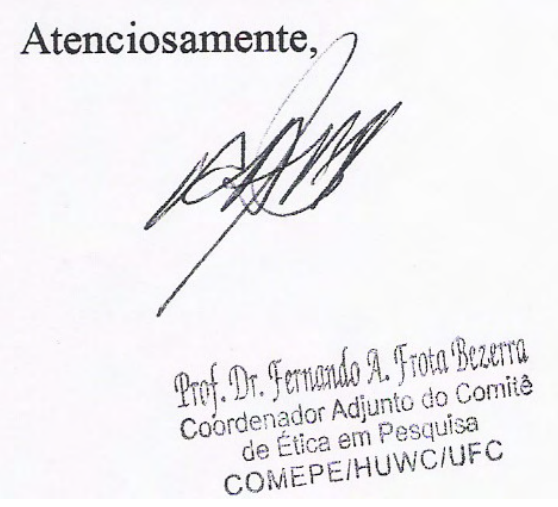

